\title{
Getting at Underlying Mechanisms of Far Transfer - the Mediating Role of Near Transfer
}

\author{
Anja Pahor \\ Corresponding Author \\ University of California, Irvine, School of Education, \\ Irvine, California, USA \\ apahor@uci.edu \\ University of California, Riverside, Department of Psychology, \\ Riverside, California, USA \\ Aaron R. Seitz \\ University of California, Riverside, Department of Psychology, \\ Riverside, California, USA \\ aseitz@ucr.edu \\ Susanne M. Jaeggi \\ University of California, Irvine, School of Education, School of \\ Social Sciences (Department of Cognitive Sciences), \\ Irvine, California, USA \\ smjaeggi@uci.edu
}




\section{Abstract}

The extent that working memory training improves performance on untrained tasks is highly controversial. Here we address this controversy by testing the hypothesis that far transfer may depend upon near transfer using mediation models in three separate randomized controlled trials (RCTs). In all three RCTs, totaling 460 individuals, performance on untrained N-back tasks (near transfer) mediated transfer to Matrix Reasoning (a measure of fluid intelligence, representing far transfer). Untrained N-back performance also mediated transfer to a working memory composite (RCT 3). These findings support a model of N-back training in which transfer to untrained n-back tasks gates further transfer, at least in the case of working memory at the construct level, and matrix reasoning. This model can help adjudicate between the many studies and meta-analyses of working memory training that have provided mixed results but have not examined the relationship between near and far transfer on an individual differences level.

Key words: working memory; training; far transfer; matrix reasoning; mediation 


\section{Introduction}

17 The potential that working memory training can transfer to untrained tasks that differ substantially

18 from the training task (so-called 'far transfer') has generated substantial excitement in regard to

19 better understanding the causal relationship between working memory and related cognitive

20 processes $^{1-6}$, as well as to applied domains where such training can provide benefits to health and

21 wellbeing ${ }^{7-10}$. In particular, the effectiveness of working memory (WM) training to improve fluid

22 intelligence has been a controversial and highly debated topic, with some meta-analyses showing

23 a small, but significant positive effect on fluid intelligence ${ }^{11-15}$, while others argue that there is no

24 evidence of generalization to fluid intelligence after training ${ }^{16,17}$. A difficulty in reconciling across

25 different studies is that individual differences in performance and learning are ubiquitous in this

26 literature, which impact average benefits ${ }^{18}$. Furthermore, training procedures and outcome

27 measures differ greatly across studies, making meaningful comparisons challenging ${ }^{19}$.

28 One of the most common tasks used in these WM training studies is the N-back, an updating task

29 that correlates significantly with measures of higher-level cognition, such as matrix reasoning ${ }^{20-}$

3024 . While there is little doubt that N-back training leads to improved performance on untrained N-

31 back tasks ${ }^{13,25-27}$, the extent to which this reflects generation of performance strategies rather than

32 improvement in monitoring and updating of WM content, or improved inhibition of items that are

33 no longer relevant, remains unknown ${ }^{25}$. If we assume the former, we have little reason to expect

34 post-test improvement on tasks that are not of the same structure as the N-back, such as matrix

35 reasoning. On the other hand, if $\mathrm{N}$-back training leads to enhanced efficiency of updating and/or

36 inhibitory control processes, such far transfer effects would be plausible. From a theoretical

37 perspective, 'near' transfer is thought to occur when the training task and outcome measure share

38 many overlapping features and presumably recruit similar processes, whereas 'far' transfer refers 
39 to improved performance on outcome measures that share fewer features with the training task.

40 While the boundaries between near and far transfer are not clear and likely fall on a continuum ${ }^{28}$,

41 several meta-analyses of working memory training studies have demonstrated that near transfer

42 effects are both more readily observable and show larger effect sizes than far transfer effects ${ }^{13,14}$.

43 Likewise, neuroimaging research suggests that the frontostriatal system mediates near transfer

44 effects whereas the dorso- and ventrolateral prefrontal cortices appear to employ domain-general

45 networks that facilitate learning more widely ${ }^{5}$.

46 Here we go beyond merely examining the effects of N-back training on matrix reasoning to attempt

47 to understand how these effects occur in the first place ${ }^{29}$. Specifically, we first present the results

48 of a retrospective study in which mediation models were used to evaluate whether the effects of

49 N-back training on matrix reasoning are transmitted via changes in an untrained variant of N-back.

50 In addition, we used an inhibitory control task as a control measure for our analyses. Even though

51 improvement in the training task itself may also serve as a useful mediator ${ }^{30}$, this information is

52 not available for control groups, nor is it necessarily indicative of near transfer. We hypothesized

53 that N-back training groups would improve on matrix reasoning (far transfer) compared to no-

54 contact control groups, and furthermore, that this effect would be mediated by post-test

55 performance on an untrained N-back task (near transfer). This model enabled us to account for

56 individual differences in responsiveness to WM training and subsequent transfer to untrained tasks,

57 and to demonstrate that transfer to matrix reasoning tasks is completely mediated by near transfer

58 in two independent datasets collected over two academic years (RCTs 1 and 2). Since demand

59 characteristics during training and potential placebo effects were not controlled for in the

60 retrospective study, we further report the results of a double-blind, pre-registered replication study

61 with an active control group in which we replicate the finding that performance on untrained $\mathrm{N}$ - 
62 back tasks mediates transfer to matrix reasoning and extend the discussion to other tasks and

63 domains.

64

65

66

67

68

69

70

71

72

73

74

75

76

77

78

79 study-specific unit of measurement differences.

80 Table 1: Linear model of predictors of post-test performance on Matrix Reasoning in the 81 retrospective study

\begin{tabular}{lcccc}
\hline & $\boldsymbol{B}$ & $\boldsymbol{S E} \boldsymbol{B}$ & $\boldsymbol{\beta}$ & $\boldsymbol{P}$ \\
\hline Constant & $0.12(-0.04-0.28)$ & 0.08 & & $p=0.140$ \\
Pre-test Matrix Reasoning & $0.66(0.56-0.76)$ & 0.05 & .60 & $p<0.001$ \\
Pre-test N-back & $0.09(-0.02-0.19)$ & 0.05 & .08 & $p=0.108$
\end{tabular}




$\begin{array}{lcccc}\text { Pre-test Countermanding } & -0.17(-0.27--0.06) & 0.05 & -.15 & p=0.002 \\ \text { Training group } & 0.23(0.03-0.43) & 0.10 & .10 & p=0.022\end{array}$

Note. $95 \%$ bias corrected and accelerated confidence intervals reported in parentheses. Confidence intervals and standard errors based on 1000 bootstrap samples. $R^{2}=.51$

82 After adding post-test N-back and Countermanding as parallel mediators (cf. Figure 1A), the total

83 effect (i.e. the sum of indirect and direct effects) of training group on post-test performance on

84 Matrix Reasoning remained significant $\left(B=.23, p=0.022, R^{2}=.50\right)$. Training group predicted

85 performance on post-test N-back $(B=1.05, p<.001)$, which in turn predicted performance on

86 post-test Matrix Reasoning $(B=0.18, p<.001)$. A bootstrap confidence interval for the indirect

87 effect (IE) based on 5,000 bootstrap samples did not include zero (IE $=0.19, \mathrm{SE}=0.05,95 \% \mathrm{CI}=$

88 0.09-0.31), providing evidence for significant mediation via post-test N-back. While training

89 group predicted post-test reaction time performance on the Countermanding task $(B=-.25, p=$

$90.159)$, this variable did not predict post-test Matrix Reasoning $(B=.07, p=.214)$, indicating that

91 this type of far transfer was not mediated by training-related improvement in inhibitory control (IE

$92=-0.02, \mathrm{SE}=0.02,95 \% \mathrm{CI}=-0.06-0.01)$. Moreover, the two indirect effects differed significantly

93 from each other $(\mathrm{IE}=0.21, \mathrm{SE}=0.06,95 \% \mathrm{CI}=0.09-0.34)$. These results suggest that the causal

94 effect of training group (No-contact control/N-back training) on matrix reasoning is mediated by

95 the extent to which participants improve on near transfer. To determine the reproducibility of these

96 results, the same analyses were conducted on the two independent RCTs.

97 RCT 1. Linear regression results revealed that training group predicted post-test Matrix

98 Reasoning $\left(B=.40, p=.048, R^{2}=.50\right)$ after controlling for pre-test Matrix Reasoning, $\mathrm{N}$-back,

99 and Countermanding. In the mediation analysis (cf. Figure 1B), the total effect of training group

100 on matrix reasoning was also significant $\left(B=.40, p=.048, R^{2}=.50\right)$. Training group predicted

101 performance on post-test $\mathrm{N}$-back $(B=1.07, p<.001)$, which in turn predicted performance on 
102 post-test Matrix Reasoning $(B=0.17, p=$

.023). A bootstrap confidence interval for the

104 specific indirect effect did not include zero

$(\mathrm{IE}=0.19, \mathrm{SE}=0.09,95 \% \mathrm{CI}=0.03-0.40)$,

106 providing evidence for significant mediation.

107 In contrast, performance on the

108 Countermanding task did not mediate the

109 relationship between training group and

110 matrix reasoning $(\mathrm{IE}=-0.02, \mathrm{SE}=0.04,95 \%$

$111 \mathrm{CI}=-0.11-0.54)$. The two indirect effects

112 differed significantly from each other (IE =

$1130.20, \mathrm{SE}=0.11,95 \% \mathrm{CI}=0.02-0.45)$.

114 RCT 2. Linear regression results suggested

115 that training group did not predict post-test

116 Matrix Reasoning $\left(B=.17, \mathrm{p}=.15, R^{2}=.51\right)$

117 after controlling for pre-test Matrix

118 Reasoning, N-back and Countermanding.
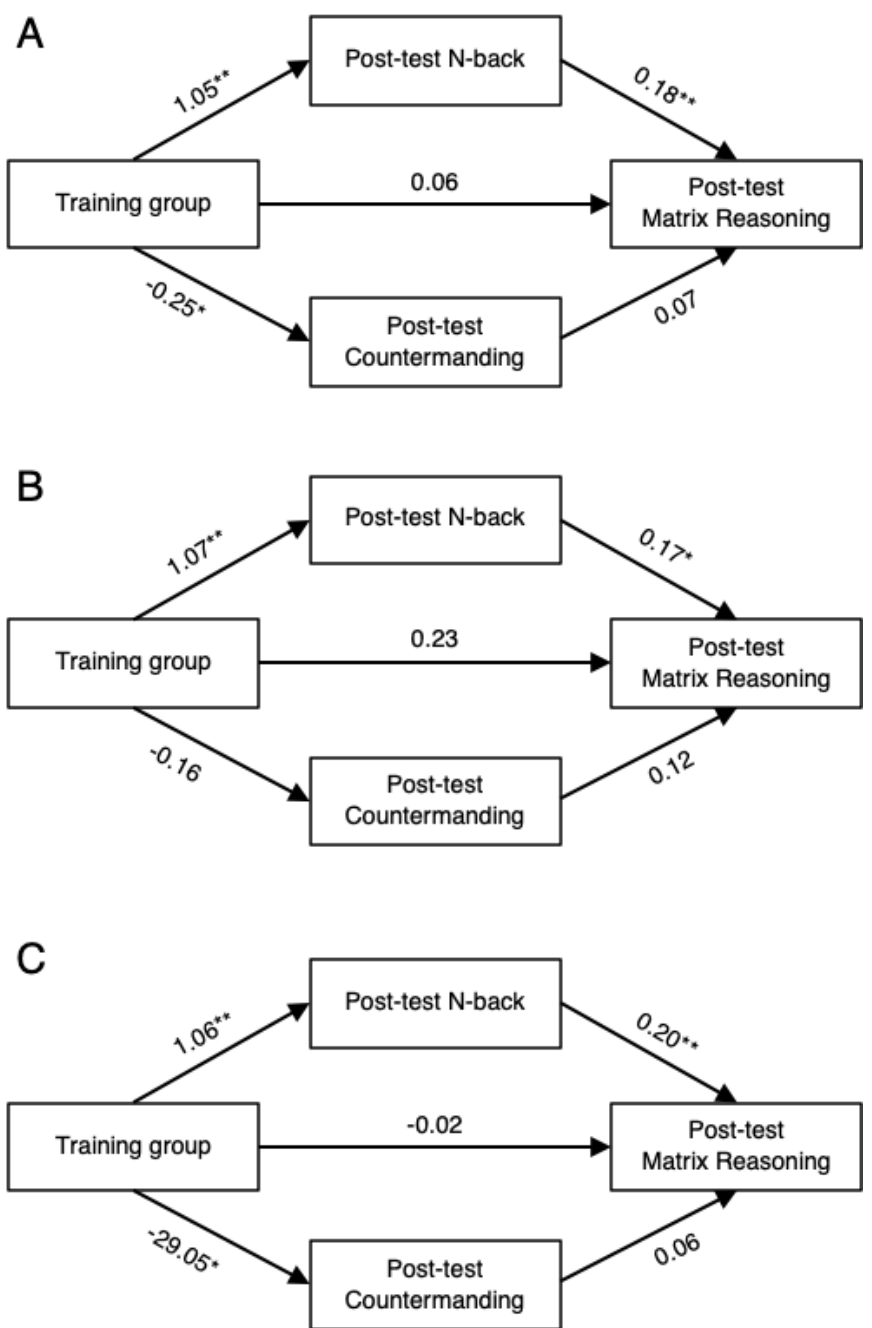

Figure 1: Parallel two-mediator models for the Whole Sample $(\boldsymbol{A} ; N=271), R C T 1(\boldsymbol{B}: N=94)$, and $R C T 2$ $(\boldsymbol{C} ; N=177)$. Path coefficients are standardized regression coefficients. Covariates (not displayed):

Pre-test $N$-back, Pre-test Countermanding and Pre-test Matrix Reasoning. ${ }^{*} p<.05, * * p<.01$.

119 Likewise, in the mediation analysis (cf. Figure 1C), the total effect of training group on matrix

120 reasoning was not significant $\left(\mathrm{p}=0.15, R^{2}=.51\right)$. Nevertheless, training group predicted

121 performance on post-test N-back $(B=1.06, p<.001)$, which in turn predicted performance on 122 post-test Matrix Reasoning $(B=0.20, p=.002)$ after controlling for baseline performance on each

123 test. At post-test, all three outcome measures correlated significantly with each other 124 (Supplementary Table 2), yet only the indirect effect through the N-back task was significant (IE 
$125=0.21, \mathrm{SE}=0.07,95 \% \mathrm{CI}=0.07-0.36$ ), whereas the indirect effect through the Countermanding

126 task was not $(\mathrm{IE}=-0.02, \mathrm{SE}=0.03,95 \% \mathrm{CI}=-0.76-0.45)$. The two indirect effects differed

127 significantly from each other $(\mathrm{IE}=0.23, \mathrm{SE}=0.09,95 \% \mathrm{CI}=0.06-0.40)$.

128 Consider two participants from this RCT who were assigned to the same training condition and 129 who showed similar training gain of about two N-levels $\left(\mathrm{S} 102_{\text {gain }}=2.25 ; \mathrm{S} 105_{\text {gain }}=2.17\right)$ yet

130 showed very different transfer to Matrix Reasoning: S105 showed no change at post-test relative

131 to pre-test in terms of accuracy, whereas subject S102 showed improved accuracy at post-test.

132 Examining untrained n-back results reveals that S105 did not show evidence of near transfer,

133 which may explain the lack of transfer to matrix reasoning, whereas S102 showed near transfer.

134 In this case, training gain has little predictive validity towards matrix reasoning outcomes. It

135 remains to be determined why these participants showed such different patterns of results - it is 136 possible that individual differences in strategy sophistication ${ }^{31}$ and/or motivation ${ }^{32}$ affected 137 training outcomes.

138 Alternative mediation models. To test the hypothesis that $\mathrm{N}$-back gains also mediate other 139 aspects of transfer, we tested whether post-test N-back mediated the relationship between training 140 group and post-test Countermanding performance (Supplementary Figure 4). This was found in 141 the whole sample (IE $=-0.23, \mathrm{SE}=0.09,95 \% \mathrm{CI}=-0.42$ to -0.08$)$ and in RCT 2 (IE $=-0.28, \mathrm{SE}$ $142=.12,95 \% \mathrm{CI}=-0.55$ to -0.08$)$, but not in $\mathrm{RCT} 1(\mathrm{IE}=-0.19, \mathrm{SE}=0.12,95 \% \mathrm{CI}=-0.46$ to 0.01$)$.

\section{Specific Training Effects and Near Transfer - N-back}

144 Substantial individual differences in N-back performance were observed both as a function of 145 training progression and at pre/post-test. For the N-back training groups, mean $\mathrm{N}$-level on the first 146 day of training ranged from 2.00 to 6.44 in RCT 1 and from 1.12 to 4.84 in RCT 2 . While these 147 results suggest large individual differences in performance of all groups, training gain showed 
148 even greater variability: on the last day of training, mean N-level ranged from 1.76 to 11.37 in

149 RCT 1 and from 2.00 to 11.00 in RCT 2, with increasing variability as a function of training time

150 (cf. Figure 5).

151 No baseline differences between N-back training and control groups were observed for the

152 untrained N-back task (average accuracy across 2-back and 3-back levels; called Near Transfer

153 hereafter) within each RCT (Supplementary Table 4). In RCT 1, pre-test accuracy on the Near 154 Transfer task ranged from .42 to .93 in the no-contact control group and from .18 to 1.0 in the $\mathrm{N}$ -

155 back training group. In RCT 2, pretest accuracy on the Near Transfer task ranged from .22 to .82

156 for no-contact control and from .27 to .85 for the N-back training group. When examining pre-post

157 effect sizes (ES) across RCTs 1 and 2, no-contact control groups showed little or no improvement

158 at post-test relative to pre-test on near transfer, whereas $\mathrm{N}$-back training groups showed a 159 substantial increase in accuracy on this task $(\mathrm{ES}=0.80-0.92$; cf. Table 2$)$.

160 Far Transfer Effects

161 No baseline differences between N-back training and control groups were observed for Matrix

162 Reasoning or Countermanding (Supplementary Table 4). The two N-back training groups showed

163 small performance benefits on Matrix Reasoning (ES $=0.43-0.49)$, whereas the control groups

164 showed negligible change in performance (ES < 0.20). Further, N-back training groups, but not

165 Control groups, showed a decrease in average RT on incongruent trials of the Countermanding 166 task, an index of inhibitory control, particularly in RCT 2 (ES = 0.44; cf. Table 2). 


\begin{tabular}{|c|c|c|c|c|c|c|c|c|c|}
\hline \multirow[t]{2}{*}{ Study } & \multicolumn{3}{|c|}{ Pre-test } & \multicolumn{3}{|c|}{ Post-test } & \multicolumn{3}{|c|}{$\begin{array}{l}\text { Paired comparisons } \\
\text { (pre vs. post) }\end{array}$} \\
\hline & $N$ & Mean & $S D$ & $N$ & Mean & $S D$ & $r$ & $d$ & $B F_{10}$ \\
\hline \multicolumn{10}{|l|}{$\begin{array}{l}\text { RETROSPECTI } \\
\text { VE STUDY }\end{array}$} \\
\hline \multicolumn{10}{|l|}{$\begin{array}{l}\text { RCT } 1 \\
\text { Near transfer }\end{array}$} \\
\hline N-back training & 72 & .61 & .16 & 72 & .80 & .20 & .15 & .80 & $>100 *$ \\
\hline $\begin{array}{l}\text { No-contact } \\
\text { control }\end{array}$ & 22 & .61 & .15 & 22 & .62 & .22 & $.52 *$ & .06 & .23 \\
\hline \multicolumn{10}{|l|}{ Matrix reasoning } \\
\hline N-back training & 72 & .72 & .13 & 72 & .76 & .14 & $.73 *$ & .49 & $>100^{*}$ \\
\hline $\begin{array}{l}\text { No-contact } \\
\text { control }\end{array}$ & 22 & .71 & .11 & 22 & .71 & .16 & $.51 *$ & -.02 & .22 \\
\hline \multicolumn{10}{|l|}{ Countermanding } \\
\hline N-back training & 72 & 832.25 & 122.81 & 72 & 803.22 & 102.78 & $.48 *$ & .25 & $1.05^{*}$ \\
\hline $\begin{array}{l}\text { No-contact } \\
\text { control }\end{array}$ & 22 & 842.87 & 112.43 & 22 & 827.22 & 136.90 & $.58 *$ & .14 & .27 \\
\hline \multicolumn{10}{|l|}{ RCT 2} \\
\hline N-back training & 109 & .59 & .15 & 109 & .78 & .18 & $.31 *$ & .96 & $>100^{*}$ \\
\hline $\begin{array}{l}\text { No-contact } \\
\text { control }\end{array}$ & 68 & .59 & .15 & 68 & .61 & .14 & $.38 *$ & .14 & .24 \\
\hline \multicolumn{10}{|l|}{ Matrix reasoning } \\
\hline N-back training & 109 & .58 & .18 & 109 & .63 & .20 & $.76^{*}$ & .43 & $>100 *$ \\
\hline $\begin{array}{l}\text { No-contact } \\
\text { control }\end{array}$ & 68 & .56 & .16 & 68 & .59 & .17 & $.52 *$ & .19 & .44 \\
\hline \multicolumn{10}{|l|}{ Countermanding } \\
\hline N-back training & 109 & 745.42 & 120.43 & 109 & 710.46 & 109.01 & $.77 *$ & .44 & $>100 *$ \\
\hline $\begin{array}{l}\text { No-contact } \\
\text { Control }\end{array}$ & 68 & 756.61 & 129.13 & 68 & 757.37 & 179.04 & $.68^{*}$ & -.01 & .13 \\
\hline \multicolumn{10}{|l|}{$\begin{array}{l}\text { REPLICATION } \\
\text { RCT } 3\end{array}$} \\
\hline \multicolumn{10}{|l|}{ Near transfer } \\
\hline N-back training & 128 & .59 & .14 & 128 & .85 & .16 & $.36^{*}$ & 1.52 & $>100 *$ \\
\hline Active control & 61 & .60 & .18 & 61 & .66 & .17 & $.63^{*}$ & .35 & $4.18^{*}$ \\
\hline \multicolumn{10}{|l|}{ Matrix reasoning } \\
\hline N-back training & 128 & .56 & .18 & 128 & .62 & .20 & $.75^{*}$ & .46 & $>100 *$ \\
\hline Active control & 61 & .57 & .21 & 61 & .61 & .21 & $.79 *$ & .36 & $5.06^{*}$ \\
\hline \multicolumn{10}{|l|}{ Countermanding } \\
\hline N-back training & 128 & 784.49 & 126.81 & 128 & 750.19 & 113.70 & $.74 *$ & .39 & $>100 *$ \\
\hline Active control & 61 & 775.01 & 15.09 & 61 & 782.83 & 18.20 & $.53 *$ & .06 & 0.16 \\
\hline \multicolumn{10}{|l|}{ Cancellation } \\
\hline N-back training & 115 & 141.50 & 19.28 & 115 & 163.77 & 22.90 & $.80^{*}$ & 1.61 & $>100 *$ \\
\hline Active control & 55 & 139.24 & 18.43 & 55 & 157.11 & 23.03 & $.66^{*}$ & 1.02 & $>100 *$ \\
\hline
\end{tabular}




\begin{tabular}{|c|c|c|c|c|c|c|c|c|c|}
\hline \multicolumn{10}{|l|}{ Running Span } \\
\hline N-back training & 115 & 23.38 & 9.33 & 115 & 26.62 & 10.72 & .09 & 0.24 & $2.23 *$ \\
\hline Active control & 55 & 24.18 & 10.25 & 55 & 26.36 & 11.09 & $.35^{*}$ & 0.18 & 0.34 \\
\hline \multicolumn{10}{|l|}{ Sequencing } \\
\hline N-back training & 115 & 8.58 & 3.28 & 115 & 9.44 & 3.74 & $.53^{*}$ & 0.25 & $2.94 *$ \\
\hline Active control & 55 & 8.62 & 3.02 & 55 & 8.47 & 2.72 & $.69 *$ & 0.06 & 0.16 \\
\hline \multicolumn{10}{|l|}{ Simple Span } \\
\hline N-back training & 115 & 52.89 & 15.08 & 115 & 54.89 & 15.28 & $.49 *$ & 0.13 & 0.27 \\
\hline Active control & 55 & 57.51 & 13.03 & 55 & 56.11 & 12.89 & .20 & 0.09 & 0.18 \\
\hline \multicolumn{10}{|l|}{ Complex Span } \\
\hline N-back training & 115 & 45.30 & 15.94 & 115 & 48.15 & 15.20 & $.57 *$ & 0.20 & 0.87 \\
\hline Active control & 55 & 45.96 & 13.26 & 55 & 45.96 & 15.19 & $.45^{*}$ & 0.00 & 0.15 \\
\hline \multicolumn{10}{|c|}{ ETS Surface Development } \\
\hline N-back training & 115 & 0.47 & 0.23 & 115 & 0.59 & 0.24 & $.69 *$ & 0.68 & $>100 *$ \\
\hline Active control & 55 & 0.48 & 0.27 & 55 & 0.62 & 0.24 & $.69 *$ & 0.72 & $>100 *$ \\
\hline \multicolumn{10}{|c|}{ ETS Space Relations } \\
\hline N-back training & 115 & 0.66 & 0.20 & 115 & 0.71 & 0.19 & $.57 *$ & 0.24 & $2.30^{*}$ \\
\hline Active control & 55 & 0.61 & 0.18 & 55 & 0.71 & 0.17 & $.44^{*}$ & 0.52 & $85.08 *$ \\
\hline \multicolumn{10}{|l|}{ DAT Form Board } \\
\hline N-back training & 115 & 50.04 & 15.78 & 115 & 57.70 & 15.34 & $.57 *$ & 0.53 & $>100 *$ \\
\hline Active control & 55 & 53.20 & 15.87 & 55 & 59.31 & 16.90 & $.75^{*}$ & 0.53 & $95.36^{*}$ \\
\hline
\end{tabular}

170 Table 2: Descriptive statistics and within-group Pearson's $r$, Cohen's $d^{(a)}$ and Bayes Factor ${ }^{(b)}$ for 171 proportion correct performance on pre-test and post-test on Near transfer (untrained N-back), 172 Matrix reasoning, Countermanding task (in ms), as well as other outcome measures separated by $173 R C T$. Extreme evidence in favor of the alternative hypothesis based on BF 10 is marked bold.

(a) Accounts for the correlation between pre- and post-test measures: $\left(\right.$ Mean $_{\text {Post }}-$ Mean $\left._{\text {Pre }}\right) /$ $\sqrt{\left(S D_{\text {Pre }}^{2}+S D_{\text {Post }}^{2}-2 r_{\text {Prepost }} * S D_{\text {Pre }} * S D_{\text {Post }}\right)}$

(b) $\mathrm{BF}_{10}$ grades the intensity of the evidence that the data provide for $\mathrm{H}_{1}$ versus $\mathrm{H}_{0} . \mathrm{BF}_{10}$ between 1 and 3 is considered to be only anecdotal evidence for $\mathrm{H}_{1}$; 3-10: moderate evidence; 10-30: strong evidence; 30-100: very strong evidence; $>100$ extreme evidence ${ }^{33,34}$. 
176 Given that near and far transfer effects were measured with single tasks, we recognize that the

177 results might still reflect task-specific learning to some extent, and as such, we make no claims to

178 the mental constructs of WM, response inhibition, and fluid intelligence. Furthermore, due to the

179 use of no-contact controls, it is possible that some of the performance advantage of N-back training

180 groups stems from non-specific characteristics of the training protocol such as participant and/or

181 experimenter expectancies and experimenter contact ${ }^{35}$. Even though a recent meta-analysis found

182 no meaningful performance difference between no-contact and active controls ${ }^{36}$, we decided to

183 conduct a pre-registered, double-blind replication study using an active control group to control

184 for these effects. Further, we expanded the test battery to extend the analyses to other outcome

185 measures and to be able to generate composite scores for each domain.

\section{Pre-registered Replication Study}

188 In RCT3, the analytical sample consisted of 189 participants: 128 participants completed 20 189 sessions of $\mathrm{N}$-back training whereas 61 participants completed 20 sessions of general knowledge 190 training (active control). The N-back training group showed similar gains on Near Transfer $(\mathrm{ES}=$

191 1.52), Matrix Reasoning $(\mathrm{ES}=0.46)$, and Countermanding $(\mathrm{ES}=0.39)$ as the training groups in

192 the retrospective study. Importantly, the basic assessment battery was expanded to include four 193 additional WM tasks (Running Span, Sequencing, Simple Span, and Complex Span), one 194 additional measure of executive function (Cancellation), and three additional spatial reasoning 195 measures (ETS Surface Development, ETS Space Relations, DAT Form Board) to be able to 196 construct composite scores in the three domains of interest. First, we present a replication of the 197 2-mediator parallel model, followed by models in which composite scores are entered as 198 mediators, and finally, models in which a composite score represents the outcome variable. 
199 Linear regression results shown in Table 3 indicate that training group was not a significant

200 predictor of post-test performance on Matrix Reasoning after controlling for pre-test performance

201 on Matrix Reasoning, N-back, and Countermanding. Note that a simple association between

202 independent and dependent variables is not necessary for mediation analysis ${ }^{37}$.

203

204 Table 3: Linear model of predictors of post-test performance on Matrix Reasoning in RCT3

\begin{tabular}{lcccc}
\hline & $\boldsymbol{B}$ & $\boldsymbol{S E} \boldsymbol{B}$ & $\boldsymbol{\beta}$ & $\boldsymbol{P}$ \\
\hline Constant & $0.25(0.08-0.41)$ & 0.09 & & $p=0.01$ \\
Pre-test Matrix Reasoning & $0.76(0.65-0.88)$ & 0.06 & .71 & $p<0.001$ \\
Pre-test N-back & $0.10(0.002-0.19)$ & 0.05 & .09 & $p=0.07$ \\
Pre-test Countermanding & $-0.15(-0.32-0.01)$ & 0.09 & -.11 & $p=0.07$ \\
Training group & $0.07(-0.12-0.29)$ & 0.10 & .03 & $p=0.50$ \\
\hline $\begin{array}{l}\text { Note. 95\% bias corrected and accelerated confidence intervals reported in parentheses. Confidence intervals and } \\
\text { standard errors based on 1000 bootstrap samples. } R^{2}=.60\end{array}$ &
\end{tabular}


205 Likewise, in the mediation analysis (cf. Figure 2A), the total effect of training group on matrix

206 reasoning was not significant $\left(\mathrm{p}=0.07, R^{2}=.60\right)$. Importantly though, the parallel mediation model

207 replicates the findings from Study 1: training group predicted performance on post-test N-back (B

$208=1.34, p<.001)$, which in turn predicted performance on post-test Matrix Reasoning $(B=0.20, p$

$209<.001)$ after controlling for baseline

210 performance on each test. A bootstrap

211 confidence interval for the specific indirect

212 effect through post-test N-back did not

213 include zero $(\mathrm{IE}=0.26, \mathrm{SE}=0.08,95 \% \mathrm{CI}=$

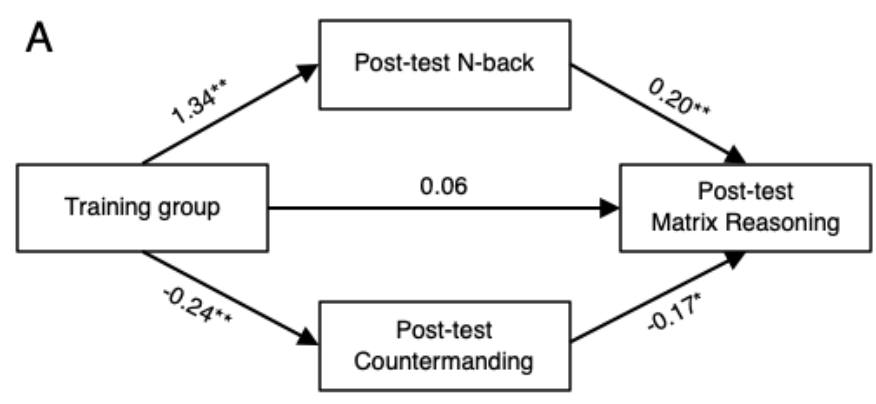

214 0.10-0.43), showing evidence for

215 significant mediation. Performance on the

216 Countermanding task did not mediate the

217 relationship between training group and

218 Matrix Reasoning (IE $=0.04, \mathrm{SE}=0.03$,

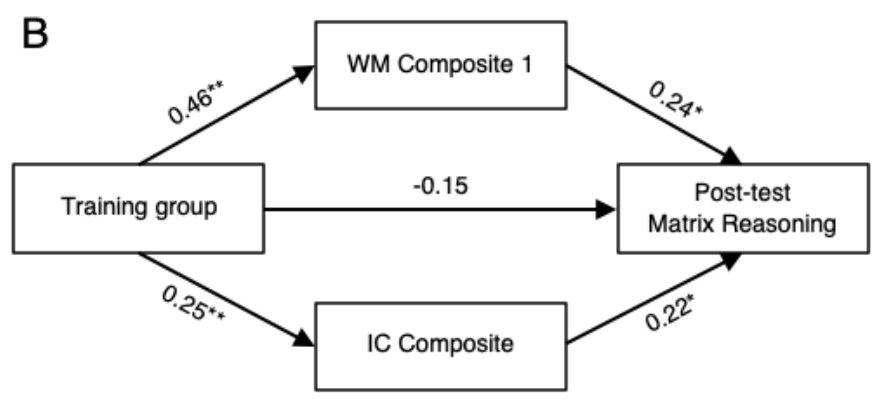

$21995 \% \mathrm{CI}=-0.003-0.11$ ), which is in line with

220 the results obtained in the retrospective

221 study. These results provide further

222 evidence that transfer to untrained N-back

223 tasks is a vital mediator through which the

224 N-back training intervention affects

225 improved performance on Matrix

226 Reasoning. Moreover, post-test

227 performance on untrained N-back preceded

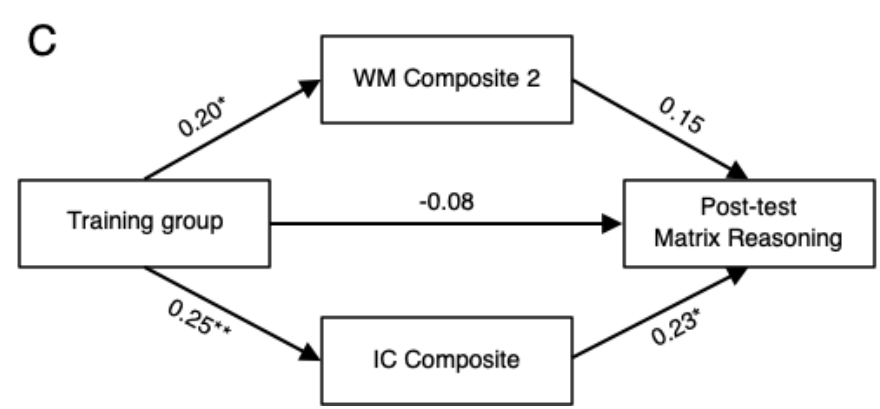

Figure 2: Parallel two-mediator models for RCT3. In all models, pre-test variables are added as covariates. Path coefficients are standardized regression coefficients. $N=170 . * p<.05, * * p<.01 \mathrm{~A}$ : Replication of Study $1(N=189)$. B: WM Composite 1 consists of N-back, Sequencing and Span tasks. IC Composite consists of Countermanding and Cancellation tasks $(N=170)$. C: WM Composite 2 consists of Sequencing and Span tasks only $(N=170)$. 
228 performance on Matrix Reasoning by one day, hence satisfying the recommendation that the

229 mediator must intervene between the predictor and the outcome ${ }^{38}$. The same pattern of results was

230 obtained when the two mediators were

231 replaced with composite scores (cf. Figure

232 2B). Note that the sample size for this and

233 subsequent analyses is smaller $(\mathrm{N}=170)$ due

234 to outliers removed on WM and inhibitory

235 control (IC) tasks. Post-test working

236 memory Composite 1, which includes the N-

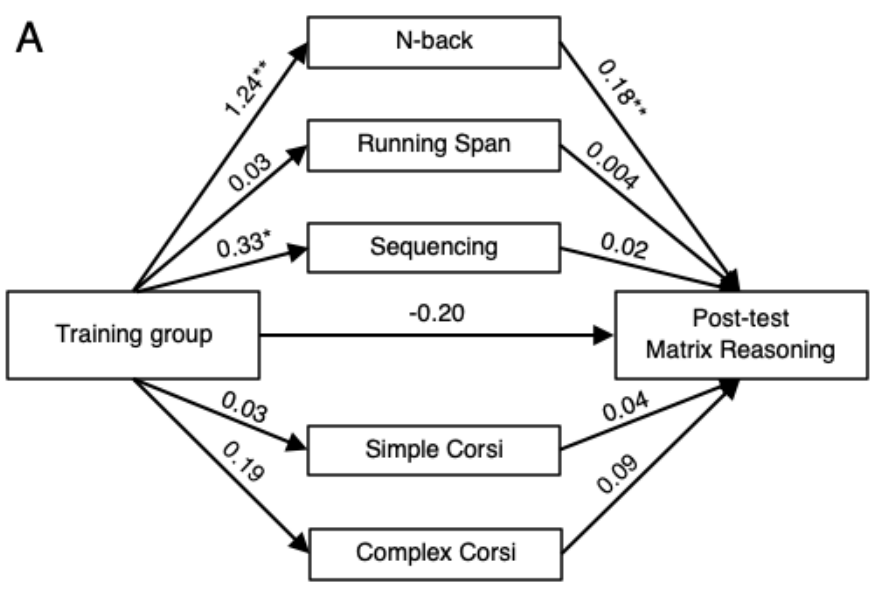

237 back task, mediated transfer to Matrix

238 Reasoning $(\mathrm{IE}=0.11, \mathrm{SE}=0.05,95 \% \mathrm{CI}=$

$2390.02-0.22$ ), whereas the IC Composite did

240 not $(\mathrm{IE}=0.05, \mathrm{SE}=0.04,95 \% \mathrm{CI}=-0.003-$

$2410.14)$ thus replicating and extending the

242 basic parallel model.

243 A question that arises is whether Matrix

244 Reasoning is mediated solely by N-back or
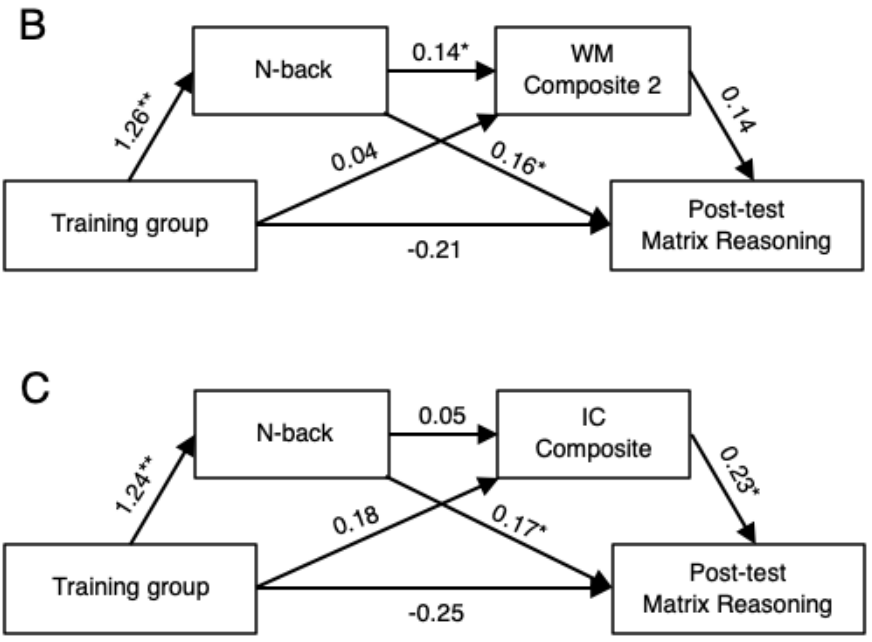

Figure 3: Alternative mediation models of transfer to

Matrix Reasoning. In all models, pre-test variables are added as covariates. Path coefficients are standardized

245 whether other WM measures contribute to regression coefficients. $N=170 . * p<.05, * * p<.01$. A: Parallel multiple-mediator model. B-C: Serial mediator the mediation as well. A multiple parallel models.

247 mediation model (cf. Figure 3A) showed that post-test N-back was the only significant mediator

248 of Matrix Reasoning performance $(\mathrm{IE}=0.22, \mathrm{SE}=0.09,95 \% \mathrm{CI}=0.07-0.41)$. The indirect effect

249 via post-test N-back was significantly different from all other indirect effects (N-back - Running

250 Span: $\mathrm{IE}=0.22, \mathrm{SE}=0.09,95 \% \mathrm{CI}=0.06-0.41 ; \mathrm{N}-$ back - Sequencing: $\mathrm{IE}=0.22, \mathrm{SE}=0.09,95 \%$ 
$251 \mathrm{CI}=0.06-0.41 ; \mathrm{N}-$ back - Simple Span: $\mathrm{IE}=0.22, \mathrm{SE}=0.09,95 \% \mathrm{CI}=0.06-0.41 ; \mathrm{N}-\mathrm{back}-$

252 Complex Span: $\mathrm{IE}=0.21, \mathrm{SE}=0.09,95 \% \mathrm{CI}=0.04-0.40)$. Given these results, it is not surprising

253 that Working Composite 2, which does not include N-back or Running Span, did not mediate the

254 relationship between training group and transfer to Matrix Reasoning performance (IE $=0.006$,

$255 \mathrm{SE}=0.004,95 \% \mathrm{CI}=-0.012-0.015)$, nor did $\mathrm{IC}(\mathrm{IE}=0.011, \mathrm{SE}=0.007,95 \% \mathrm{CI}=-0.001-0.027)$

256 (cf. Figure 2C).

257 In the literature, untrained N-back is often seen as very near transfer, while structurally different

258 WM tasks are classified as near transfer and non-WM tasks as far transfer ${ }^{13}$, implying a serial

259 relationship among these task domains. While unlikely given the results above, a serial mediation

260 model $^{c}$, in which the first mediator was post-test N-back and the second mediator was post-test

261 Working Memory Composite 2, was ran to test this hypothesis (cf. Figure 3B). As expected, the

262 indirect specific effect via untrained N-back was significant (Condition $\rightarrow$ N-back $\rightarrow$ Matrix

263 Reasoning: $\mathrm{IE}=0.20, \mathrm{SE}=0.09,95 \% \mathrm{CI}=0.04-0.39)$ whereas the two indirect effects that

264 included the working memory composite were not (Condition $\rightarrow$ WM Composite $2 \rightarrow$ Matrix

265 Reasoning: $\mathrm{IE}=0.01, \mathrm{SE}=0.02,95 \% \mathrm{CI}=-0.03-0.05 ;$ Condition $\rightarrow \mathrm{N}-$ back $\rightarrow$ WM Composite

$2662 \rightarrow$ Matrix Reasoning: $\mathrm{IE}=0.02, \mathrm{SE}=0.02,95 \% \mathrm{CI}=-0.01-0.06)$.

267 Since overriding dominant or prepotent responses is also required during N-back training (e.g.,

268 when switching N-levels, the player must inhibit responses related to the previous level), and this

269 may play a role in solving matrix reasoning tasks, we replaced the second mediator (WM

270 Composite 2) with the IC composite (cf. Figure 3C). Results showed that only the path via N-back

271 mediated transfer to Matrix Reasoning (Condition $\rightarrow$ N-back $\rightarrow$ Matrix Reasoning: IE $=0.21$, SE

\footnotetext{
c Serial mediation models were not pre-registered and were added post-hoc.
} 
$272=0.09,95 \% \mathrm{CI}=0.05-0.38)$, whereas the two indirect effects that included the IC composite were

273 not significant (Condition $\rightarrow$ IC Composite

$274 \rightarrow$ Matrix Reasoning: $\mathrm{IE}=0.04, \mathrm{SE}=0.03$,

$27595 \%$ CI $=-0.01-0.12 ;$ Condition $\rightarrow$ N-back

$276 \rightarrow$ IC Composite $\rightarrow$ Matrix Reasoning: IE $=$

$2770.02, \mathrm{SE}=0.02,95 \% \mathrm{CI}=-0.01-0.05)$.

278 Overall, single mediator models explained

279 the data better than serial models.

280 There is no evidence that N-back training led

281 to improved performance on other measures

282 of visuospatial reasoning (ETS and DAT

283 tests) relative to the active control group (cf.

284 Table 1). Nevertheless, as planned during

285 preregistration, we ran a mediation model in

286 which post-test N-back and Countermanding

287 were entered as mediators and a $\mathrm{G} f$ composite

288 involving Matrix Reasoning, ETS and DAT

289 tests was entered as the outcome variable.
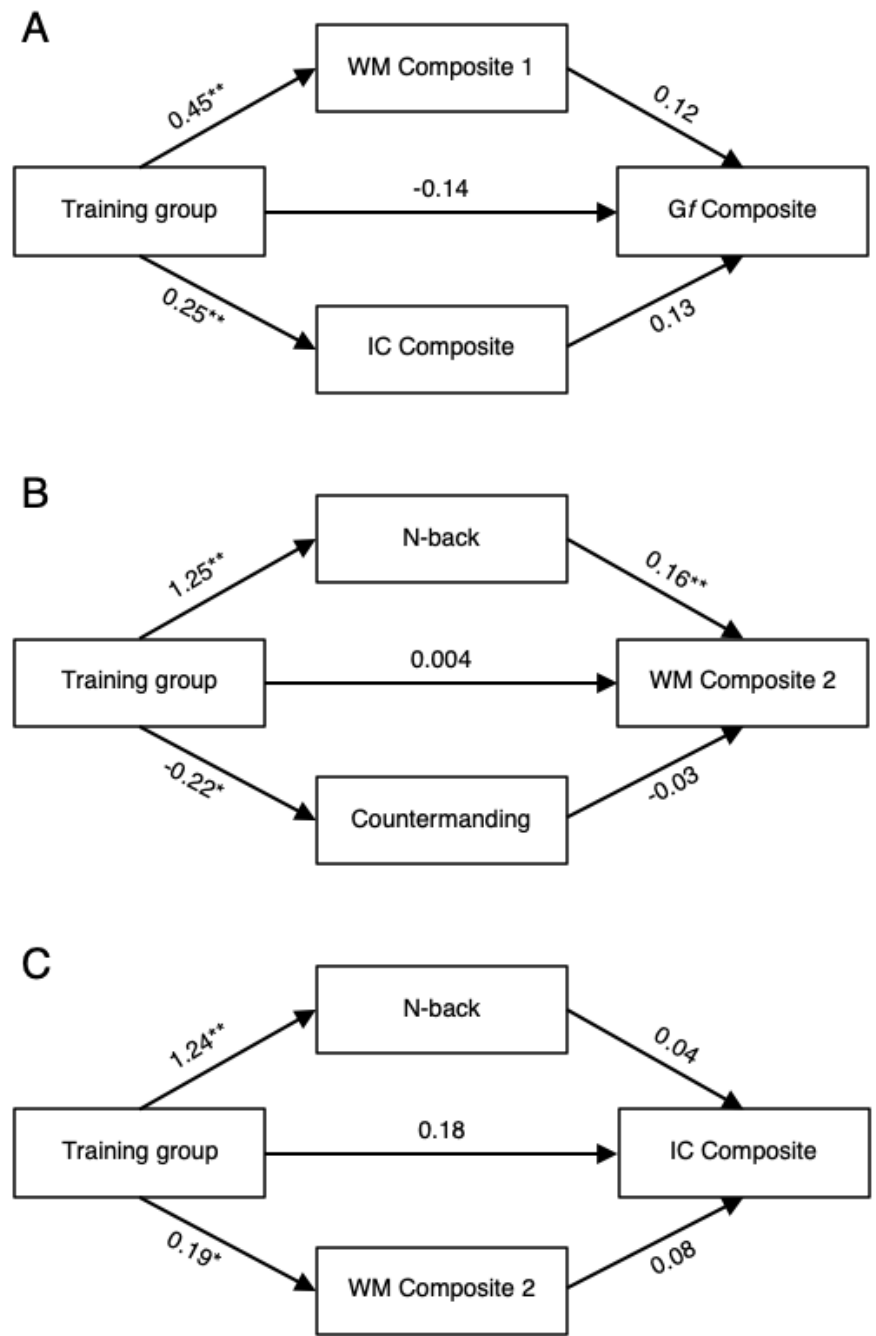

Figure 4: Alternative parallel two-mediator models for $R C T 3$ wherein the dependent variables are post-test $G f$ $(\boldsymbol{A})$, Working Memory $(\boldsymbol{B})$, and Inhibitory Control $(\boldsymbol{C})$ composite scores. In all mediation models, pre-test variables are added as covariates. Path coefficients are standardized regression coefficients. $N=170 . * p<.05$, $* * p<.01$.

290 While training group (N-back/active control) predicted performance on post-test N-back $(B=1.32$,

$291 p<.001)$ and on post-test Countermanding $(B=-0.24, p<.001)$, neither N-back $(\mathrm{IE}=0.06, \mathrm{SE}=$

$2920.05,95 \% \mathrm{CI}=-0.03-0.16)$ nor Countermanding $(\mathrm{IE}=0.02, \mathrm{SE}=0.02,95 \% \mathrm{CI}=-0.004-0.07)$

293 predicted performance on the $\mathrm{G} f$ composite after controlling for baseline performance on these 
294 tests. The same pattern of results was obtained when WM composite 1 and IC were entered as 295 mediators (cf. Figure 4A).

\section{Alternative mediation models}

298 Taking a step back, we investigated whether N-back training-related changes are observed in WM 299 tasks beyond untrained N-back and what the mechanisms might be that support this process. 300 Specifically, we tested whether performance on untrained N-back mediates transfer to a WM 301 composite consisting of sequencing and spatial span tasks (cf. Figure 4B) while entering post-test 302 Countermanding as a control mediator. Results showed that performance on untrained N-back (IE $303=0.20, \mathrm{SE}=0.06,95 \% \mathrm{CI}=0.07$ to 0.30$),$ but not Countermanding $(\mathrm{IE}=0.01, \mathrm{SE}=0.02,95 \%$

$304 \mathrm{CI}=-0.04$ to 0.05$)$, mediated transfer to the WM composite. In addition, the total effect of training 305 group on post-test WM composite performance was significant $\left(\mathrm{p}=0.03, R^{2}=.65\right)$. These results 306 suggest that the effectiveness of the N-back training intervention to improve working memory 307 ability depends on the extent to which an individual shows improvement on untrained N-back 308 tasks. The same results were obtained when the Countermanding mediator was replaced with an 309 IC composite consisting of Countermanding and Cancellation tasks (IE via IC $=0.02, \mathrm{SE}=0.02$, $31095 \% \mathrm{CI}=-0.01$ to 0.06$)$.

311 We also ran a mediation model in which the IC composite was entered as the dependent variable.

312 The indirect specific effects via untrained N-back ( $\mathrm{IE}=0.05, \mathrm{SE}=0.05,95 \% \mathrm{CI}=-0.04$ to 0.15$)$

313 and $\mathrm{WM}$ Composite 2 ( $\mathrm{IE}=0.02, \mathrm{SE}=0.02,95 \% \mathrm{CI}=-0.01$ to 0.06 ) were not significant.

314 However, the total effect of training group on $\mathrm{IC}$ was significant $(\mathrm{IE}=0.25, \mathrm{SE}=0.08,95 \% \mathrm{CI}=$ 3150.09 to 0.40 ), suggesting that N-back-training boosted IC performance relative to control training 316 (cf. Figures 4C and 6), but that this process is independent of improvements in WM. 
318 The N-back training group in RCT3 showed

319 similar training performance as in the

320 retrospective study, particularly with respect to

321 RCT 2 (cf. Figure 5). Mean N-level on the first

322 day of training ranged from 2.00 to 3.94 and on

323 the last from 2.00 to 14.33 . Likewise, individual

324 differences were observed on the Near Transfer

325 task with pre-test accuracy ranging from .22 to

326.95 in the active control group and from .23 to

327.95 in the N-back training group.

329 Far Transfer Effects

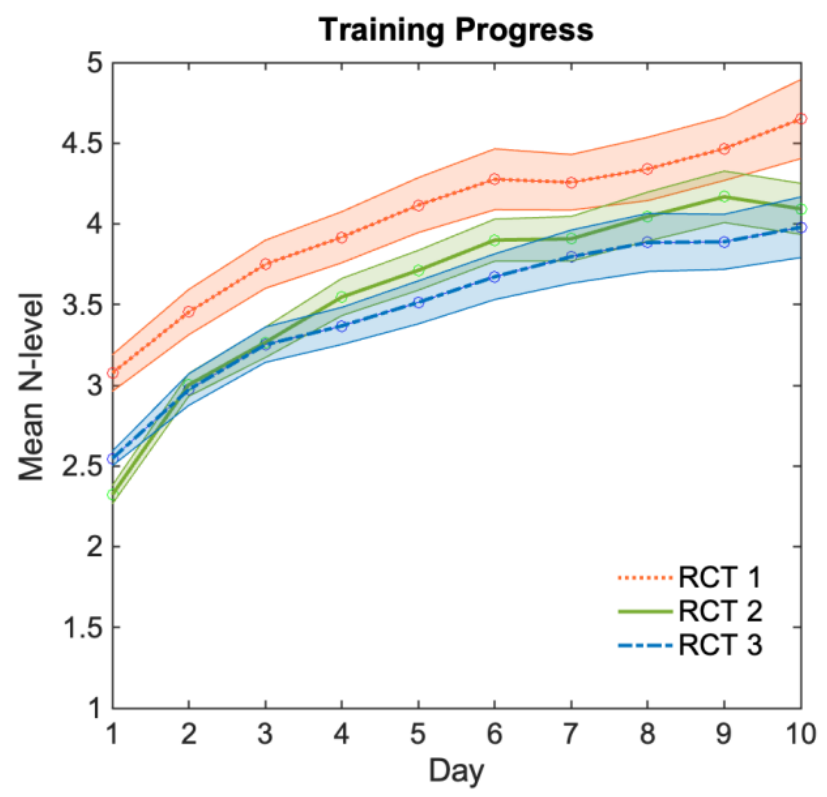

Figure 5: Average n-level achieved per day (40 minutes of training), for the $\mathrm{N}$-back training groups, weighted by the number of trials. RCT differences may reflect the use of slightly different adaptive algorithms. Shaded areas represent standard error of the mean.

330 No baseline differences between N-back training and active control groups were observed for

331 Matrix Reasoning or any of the other outcome measures (Supplementary Table 4). To confirm the

332 results of mediation analyses, Bayesian repeated measures ANOVAs with within-subjects factor

333 Time (Pre/Post) and between-subjects factor Group (Control, N-back Training) were conducted

334 on composite scores (not preregistered). Inclusion Bayes Factor across matched models (BFincl)

335 were used to evaluate evidence of Time $\times$ Group interactions. Significant interactions in favor of

336 the N-back training group (cf. Figure 6) were obtained for WM composite $1\left(\mathrm{BF}_{\text {incl }}>100\right)$, WM

337 composite $2\left(\mathrm{BF}_{\text {incl }}=2.46\right), \mathrm{IC}$ composite $\left(\mathrm{BF}_{\text {incl }}=9.59\right)$, but not the $\mathrm{G} f$ composite $(\mathrm{BF}$ incl $=0.22)$,

338 which is in line with the results reported above. 

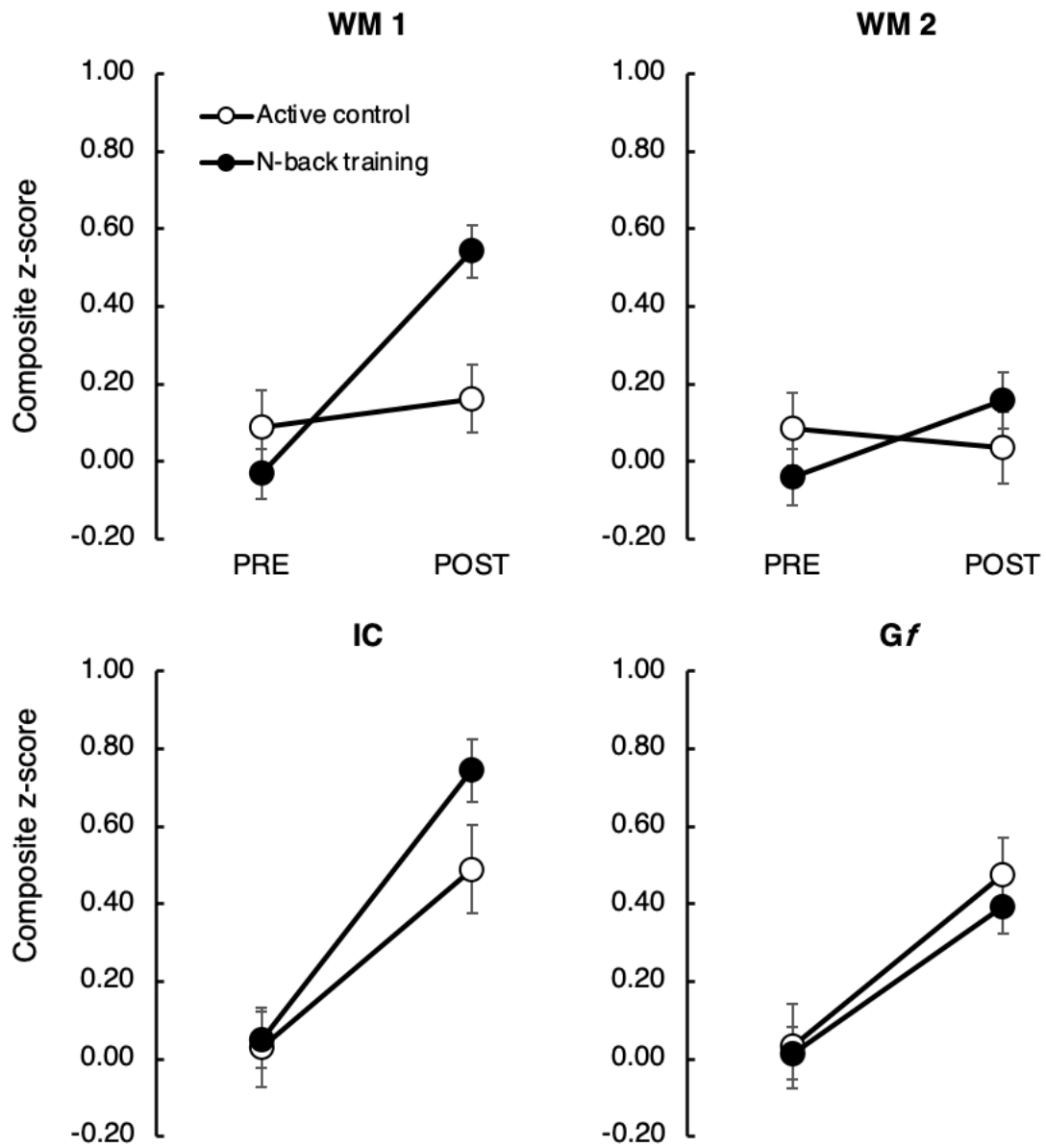

IC

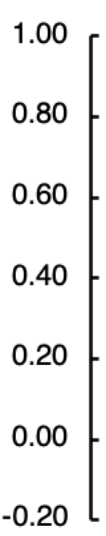

Gf
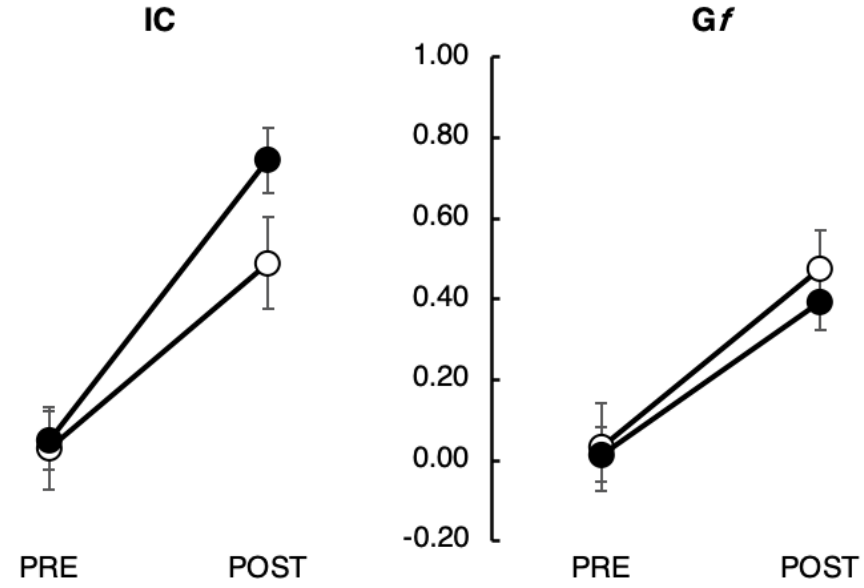

Figure 6: Pre- and post-test composite z-scores for N-back training (black circle) and Active Control (white circle) groups. WM 1: untrained N-back, Sequencing, Simple Span, and Complex Span; WM 2: Sequencing, Simple Span and Complex Span; IC composite: Countermanding and Cancellation; Gf Composite: UCMRT, ETS Surface Development, ETS Space Relations, and DAT Form Board. 


\section{Discussion}

345 Previous studies have examined the relationship between training gain and far transfer, typically

346 by comparing subgroups of participants who show low versus high training gain ${ }^{30,39,40}$; however,

347 this type of responder analysis can be problematic ${ }^{41}$. Here we demonstrate that there are alternative

348 ways of analyzing transfer data that do not involve dichotomization and may reveal concealed

349 associations and mechanisms to explain the effects of training. Three independent datasets from

350 three separate RCTs involving a total of 460 participants showed that the mechanism that underlies

351 transfer to matrix reasoning appears to be near transfer as measured by performance on untrained

352 N-back tasks. This may explain some of the variability seen in the literature that reports only

353 sporadic transfer to matrix reasoning. Importantly, transfer to untrained N-back tasks is often not

354 reported, and thus, information is often missing about what participants learned, and thus, the

355 extent of learning on measures of transfer remains unknown. For example, in a meta-analysis of

356 WM training studies ${ }^{13}, 35$ experiments measured fluid intelligence, 28 experiments assessed WM,

357 including tasks that correlate poorly with the $\mathrm{N}-\mathrm{back}^{24}$, but only 9 experiments also included 358 untrained N-back tasks. In another meta-analysis of N-back training studies, only $37 \%$ of N-back

359 training studies reported using $\mathrm{N}$-back tasks as an outcome measure ${ }^{19}$, thus for the majority of 360 studies, information is missing about what participants gained. If we do not know whether the 361 minimal amount of near transfer occurred (e.g., to a different stimulus set), then how can we gauge 362 improvements in WM and to far transfer measures beyond WM such as fluid intelligence tasks?

364 Our retrospective working memory training study using a no-contact control group showed that 365 the mechanism that underlies transfer to matrix reasoning appears to be near transfer as measured 366 by performance on untrained N-back tasks - at least in the two independent datasets collected in 
367 our lab. An important outcome of these results is that N-back training does not seem to merely

368 enhance task-specific strategies, but presumably leads to changes in underlying components of

369 WM such as the capacity of the focus of attention ${ }^{42}$ or updating $^{43}$, which supports performance on

370 matrix reasoning problems ${ }^{44}$. Understanding how this occurs is a challenge, which is constrained

371 by the lack of agreement about why WM and fluid intelligence correlate positively in the first

372 place. One explanation suggests that WM is needed to maintain rules in mind to successfully solve

373 matrix reasoning problems ${ }^{45}$. This was not supported in a subsequent study, instead, the ability to

374 manage proactive interference appeared to play a role in both constructs ${ }^{46}$. Similarly, it has been

375 shown that WM helps keep previously learned rule combinations from interfering when solving

376 problems that require a new rule combination ${ }^{47,48}$. However, since inhibitory control did not

377 mediate transfer to matrix reasoning, the present results do not support interference-type accounts.

378 Recent evidence also challenges these accounts, showing that the relationship between WM

379 capacity and matrix reasoning can be explained by individuals' ability to maintain how they solved

380 previous problems in memory ${ }^{49}$. Our results are therefore in line with research showing that

381 updating $^{43}$ and/or executive attention ${ }^{52}$, but not inhibition, show strong relations with fluid

382 intelligence. Finally, it has been argued that WM and fluid intelligence are complementary

383 processes that promote complex cognition, wherein the first reflects maintenance and the other

384 disengagement, and both serve a single top-down executive attention ${ }^{50}$. Extending this to the neural

385 level, it is plausible that transfer occurs if the training and transfer tasks engage overlapping

386 processes and neural circuits ${ }^{26,51}$.

388 To verify this finding using a more rigorous design, we pre-registered a double-blind replication

389 study and included an active control group, which was conducted online due to a ban on in-person 
research amidst the COVID-19 pandemic. Further, we investigated whether the mediation model

391 replicates using composite scores of WM, inhibitory control, and fluid intelligence as outcome

392 measures. This study provided three important findings. First, we replicate the finding that transfer

393 to Matrix Reasoning depends on the extent to which individuals show near transfer as measured

394 by performance on untrained N-back, even after controlling for participant and/or experimenter

395 expectancies with the use of an active control group and full blinding procedures. Overall, this key

396 finding has now been observed in 3 independent RCTs that included a total of 460 individuals.

397 Second, no working memory measure other than the N-back task mediated transfer to Matrix

398 Reasoning, even though post-test performance on all WM tasks except for Running Span

399 correlated significantly with Matrix Reasoning performance (Supplementary Table 5). Span-based

400 WM tasks might not share enough variance with Matrix Reasoning to explain individual

401 differences in transfer, or the gain on these tasks might not be large enough to have an observable

402 effect on transfer.

403 Third, it was shown that N-back-training led to small but significant improvements in a WM 404 composite consisting of sequencing and span-based tasks and to enhanced IC performance relative 405 to control training. Interestingly, untrained N-back performance only mediated transfer to the WM 406 composite and not the IC composite. Transfer to sequencing and/or complex WM tasks has been 407 reported by some ${ }^{53-59}$, but not other N-back training studies ${ }^{54,60-66}$. Likewise, there is no consensus 408 regarding transfer to inhibitory control measures, with some WM training studies reporting 409 training-related benefits $55,56,67,68$, yet others failing to find evidence of transfer ${ }^{51,69}$. Note that 410 previous research often included Stroop tasks as an IC measure, whereas here we used a composite 411 score based on speed of inhibitory control and a timed test of selective attention. Along with using 412 a consistent set of measures across studies ${ }^{19}$, another solution that could bring some clarity is 
413 examining individual differences in training and transfer with mediation and moderation analyses.

414 For example, we used serial mediation models to confirm that viewing untrained N-back as very

415 near transfer, which in turn affects transfer to other WM tasks, or to an inhibitory control

416 composite, and finally to Matrix Reasoning, does not explain the results. Instead, training-related

417 improvement in inhibitory control could be seen as a separate form of (far) transfer, and the

418 processes that underly this change seem to be somewhat independent. There was no systematic

419 change in $\mathrm{G} f$ tasks as a function of WM training, and N-back did not mediate transfer to this

420 composite. The matrix reasoning task used here (called UCMRT) has been shown to correlate

421 highly with performance on Raven's Advanced Progressive Matrices ${ }^{70}$; however, the correlations

422 between UCMRT and spatial visualization measures used here were much lower, especially for

423 Surface Relations and Form Board (cf. Table 4), suggesting that the tasks share few communalities.

424 While UCMRT requires some spatial visualization, it is thought to tap mainly into abstract

425 reasoning and logical problem solving. Thus, it is possible that UCMRT captures variance that's

426 shared with N-back but is different from the spatial visualization tasks used here.

428 Overall, our findings challenge the notion that WM training only leads to performance gains in 429 tasks that are closely related to the training ${ }^{71}$ and indicate that untrained N-back tasks provide 430 important information regarding the effectiveness of an N-back intervention and should therefore 431 be included as an outcome measure in future work. It remains to be seen whether a similar 432 association between untrained tasks and transfer applies to other types of cognitive training 433 paradigms or other types of transfer measures, including those capturing real-world performance.

434 x Moreover, these results can inform studies examining neuroplastic changes associated with WM 435 interventions, predicting weaker far transfer effects in individuals who show little to no near 
436 transfer, both in terms of behavior and related plastic neural changes. From a practical perspective, 437 a near transfer test administered half-way or early in the WM training intervention could indicate 438 the likelihood of far transfer. If participants struggle in near transfer tasks at this point, and as such, 439 far transfer appears unlikely, pivoting to a different type of intervention or providing additional 440 support in terms of effective strategy use ${ }^{72}$ could be beneficial to study outcomes (but see ${ }^{73}$ ). This 441 simple yet presently untested step could help maximize the effectiveness of WM training 442 interventions.

444 In sum, it is not surprising that inter-individual differences in responsiveness to WM training 445 interventions exist ${ }^{74,75}$ - in non-invasive brain stimulation studies ${ }^{76,77}$ or other intervention studies, 446 such as those focusing on physical exercise or nutrition ${ }^{78-81}$, 'non-responders' are routinely 447 excluded from data analyses or treated differently. To fully understand the underlying mechanisms 448 of WM training, future research should depart from the traditional approach that attempts to 449 determine whether an effect is present or not, and instead focus on how, for whom and why these 450 effects occur ${ }^{30,82}$. With the rise of precision medicine ${ }^{83}$, investigating the efficacy of personalized 451 cognitive training interventions ${ }^{84,85}$ will become increasingly important and ultimately, maximize 452 intervention outcomes. 


\section{Methods}

\section{Retrospective study}

\section{Participants}

458 Our sample consisted of 283 participants from the Universities of California, Riverside and Irvine, 459 collected over two academic years: Winter - Spring $2017\left(\mathrm{~N}_{\mathrm{RCT} 1}=102\right)$ and Fall 2017 - Spring $4602018\left(\mathrm{~N}_{\mathrm{RCT} 2}=181\right)$. Participants were randomly assigned either to N-back training $(\mathrm{N}=191)$ or 461 to no-contact control $(\mathrm{N}=92)^{(\mathrm{d})}$ and completed all sessions in laboratories at the respective 462 universities. They were included if they completed all pre- and post-assessments as well as at least 4638 out of 10 training days (N-back training group). Participants provided informed consent and 464 received monetary compensation for participation. The sample was relatively diverse, with 31$46540 \%$ of participants identifying as Hispanic or Latinx and 42-44\% identifying as Asian 466 (Supplementary Table 6). All procedures were approved by the UCR and UCI Institutional Review 467 Boards.

\section{Procedure}

469 Training and testing were administered on tablet computers via software developed in-house 470 ("Recollect the Study" ${ }^{86}$ ) , in combination with Qualtrics Software used to administer surveys and 471 certain assessments (Qualtrics, Provo, UT). Participants completed pre- and post-test with a 10472 day gap (excluding weekends), and in addition, the N-back training groups completed up to 10 473 working days of training. Across both RCTs, a variety of assessment tasks were used, including 474 measures of WM, selective attention, mathematical problem solving, decision making, and 475 convergent thinking, however, in order to maximize power, here, we only focus on the results of

\footnotetext{
(d) Unequal sample size reflects randomization to multiple training conditions and one no-contact condition.

e The same software for testing and training was used in both experiments.
} 
476 the 3 tasks that were used by both RCTs and which did not undergo major changes from one year

477 to the next ${ }^{(f)}$. Moreover, our goal was to test the specific hypothesis that a simple mediation model

478 focusing on N-back and Matrix Reasoning can explain a substantial amount of variance in the data.

\section{$479 \quad$ Training tasks}

480 N-back training. Participants trained on an N-back task ("Recollect the Study" 86 ) for 10 working 481 days, each day consisting of two 20-minute training sessions separated by a 10-20 minute break.

482 Training parameters were varied in that they differed in terms of N-level progression, gamification,

483 and reinforcement, but since these are not relevant to the present hypothesis, the data were 484 collapsed across N-back training conditions. To provide context, in gamified N-back training, 485 participants played a platform game called "Recollect the Study" (video can be found 486 here: https://www.youtube.com/watch?v=zhgL8Oe42Yk) in which they were tasked with 487 collecting stimuli that match those presented N items earlier. Stimuli consisted of simple colored 488 objects and were paired with unique sounds to support multisensory processing of said objects ${ }^{59}$. 489 In nongamified N-back training ("Tapback": 490 https://www.youtube.com/watch?v=GMGiDnJ53RU), a series of colored circles was presented on 491 a plain background and the participant tapped on the circles that were the same color as those 492 presented $\mathrm{N}$ items earlier. In all training paradigms, stimuli were presented for $2500 \mathrm{~ms}$ (ISI = 500 $493 \mathrm{~ms}$ ), of which $30 \%$ were targets and another $30 \%$ lures (e.g. items that occur $\mathrm{N}-1$ or $\mathrm{N}+1$ of the 494 target position $)^{86}$. The session was broken into short $\sim 2$ minute training blocks with typically $7-10$ 495 blocks per training session. Auditory and visual feedback was presented on every trial indicating 496 correct or incorrect responses. Task difficulty was adaptively adjusted based on performance either

\footnotetext{
${ }^{(f)}$ Many of the measures not included here were being continuously developed for the use of tablets and were included in the studies for validation purposes.
} 
within or between blocks depending upon the training condition. The outcome measure used here was average $\mathrm{N}-$ level per day (weighted across the number of trials within each block).

Near transfer $\mathrm{N}$-back. We used an untrained N-back task with two versions, featuring pictures of animals or vehicles. The versions were counterbalanced across individuals and sessions, with the exception of $40 \%$ of participants in RCT 1, who completed the same version twice due to a 502 technical error ${ }^{(g)}$. All participants completed 1-back, followed by 2- and 3-back tasks. Before each 503 level started, there were 10 trials of practice during which performance feedback was provided. In

504 RCT 1, the test phase for each N-level consisted of $20+\mathrm{N}$ trials with 6 targets, whereas in RCT 5052 , each $\mathrm{N}$-level consisted of $30+\mathrm{N}$ trials with 9 targets $(30 \%$ target and $30 \%$ lure rates in both RCTs). Progression to 4-back (and beyond) was allowed if the participant made no more than 2 errors on the previous level, otherwise, the task stopped at 3-back. Accuracy was calculated for each N-level as hits/(hits + misses + false alarms), allowing for comparison across RCTs. 1-back accuracy was very high $\left(\mathrm{RCT} 1:\right.$ Mean ${ }_{\text {pre }}=.88, \mathrm{SD}_{\text {pre }}=.18, \mathrm{Mean}_{\text {post }}=.94, \mathrm{SD}_{\text {post }}=.14 ; \mathrm{RCT} 2$ :

510 Mean $_{\text {pre }}=.90, \mathrm{SD}_{\mathrm{pre}}=.16$, Mean post $=.95, \mathrm{SD}_{\mathrm{post}}=.11 ;$ ) and only $7.4 \%$ and $4.8 \%$ of participants

511 reached N-levels higher than 3 at pre-test respectively, thus, we used average accuracy across 2-

512 back and 3-back levels as the dependent variable (at least $40+\mathrm{N}$ trials per participant).

513 Matrix Reasoning. Matrix reasoning problems were used to assess nonverbal problem solving 514 ability $^{87}$. Different versions of the test were used at pre-test and post-test, counterbalanced across 515 participants. While the number of problems and certain design features differed in the two RCTs, 516 the basic structure of the task remained the same. Namely, each problem consisted of a $3 \times 3$ matrix 517 with the lower right entry missing, and the participants were asked to select 1 out of 8 answer

\footnotetext{
(g) Mann-Whitney tests indicated that there were no significant performance differences at post-test as a function of test version (different versus the same) in the no-contact $(U=40, z=-.54, p=.88)$ and N-back training $(U=624, z$ $=-1.01, p=.27$ ) groups.
} 
518 options that best completes the matrix. Prior to the test phase, participants were presented with

519 example problems and the opportunity to practice the task, during which feedback was provided.

520 In RCT 1, participants were required to solve 42 problems with a time limit of 20 minutes ${ }^{87}$, 521 whereas in RCT 2, participants solved 23 problems with a time limit of 10 minutes $(\mathrm{UCMRT})^{70}$.

522 The main outcome measure in both RCTs was the proportion of correctly solved problems; for

523 RCT 1 there was a larger number of easy problems (i.e. one- and two-relation problems) than used 524 in RCT 2, hence, accuracy was higher for RCT 1 (cf. Table 1).

525 Countermanding task. A modified countermanding task was used to assess inhibitory control ${ }^{88,89}$.

526 A series of pictures appeared either on the left or the right of the screen and participants were 527 instructed to quickly and accurately tap one of 2 buttons presented below. The task involved 528 pressing the button on the same side of the screen in response to pictures of a dog (congruent trials) 529 and the button on the opposite side in response to pictures of a monkey (incongruent trials). There 530 were 3 blocks of trials, each preceded by a practice session: block of 12 congruent trials, block of 53112 incongruent trials, and a mixed block of 48 trials where congruent and incongruent trials were 532 randomly intermixed. The main dependent measure was reaction time (RT) for correct responses 533 on incongruent trials of the mixed block $^{(\mathrm{h})}$ (index of inhibitory control).

\section{Outliers and Exclusions}

535 Six outliers were removed from the sample based on performance on near transfer and matrix 536 reasoning $(\mid$ Zaccuracy $\mid>3$ at pre- or post-test separately for each RCT). In the N-back training group, 5376 additional participants were removed due to a software error in the training program. The final

\footnotetext{
(h) All RCTs showed high accuracy in the mixed block: 97\% on average or higher at pre-test and post-test.
} 
538 analytical sample consisted of 271 participants, 181 in the N-back training group and 90 in the no-

539 contact control group (cf. Table 4).

540 Table 4: Demographics of the two studies.

\begin{tabular}{lcccccc}
\hline & \multicolumn{3}{c}{ RETROSPECTIVE STUDY } & \multicolumn{2}{c}{ REPLICATION STUDY } \\
\hline & \multicolumn{2}{c}{ RCT 1 } & \multicolumn{2}{c}{ RCT 2 } & \multicolumn{2}{c}{ RCT 3 } \\
& $\begin{array}{l}\text { N-back } \\
\text { training }\end{array}$ & $\begin{array}{c}\text { No-contact } \\
\text { control }\end{array}$ & $\begin{array}{c}\text { N-back } \\
\text { training }\end{array}$ & $\begin{array}{c}\text { No-contact } \\
\text { control }\end{array}$ & $\begin{array}{c}\text { N-back } \\
\text { training }\end{array}$ & $\begin{array}{c}\text { Active } \\
\text { control }\end{array}$ \\
\hline Age & $19.96(1.75)$ & $20.56(1.72)$ & $20.01(2.90)$ & $20.26(2.35)$ & $20.70(4.07)$ & $20.50(1.82)$ \\
Female & 55.56 & 36.36 & 61.47 & 73.53 & 76.56 & 81.97 \\
Male & 41.67 & 45.45 & 37.61 & 22.06 & 21.10 & 18.03 \\
Gender Unknown & 2.78 & 18.18 & 0.92 & 4.41 & 2.34 & 0 \\
\hline $\mathrm{N}$ & 72 & 22 & 109 & 68 & 128 & 61 \\
\hline
\end{tabular}

Note. Mean age in years with standard deviation in brackets, gender (\%) and sample size (N). Ethnicity/race is reported in Supplementary Table 6.

\section{Data analysis}

543 Bayesian Paired Samples T-Tests with default priors were used to estimate changes in performance

544 as a function of time separately for each condition and RCT (cf. Table 1) in JASP ${ }^{90}$. All variables

545 were z-transformed (based on pre-test scores, separately for each RCT) prior to regression-based

546 analyses to control for RCT effects. Linear regression was used to test the relative contributions of

547 training group (N-back training, Control), pre-test Matrix Reasoning scores, pre-test N-back, and

548 pre-test Countermanding on post-test performance on Matrix Reasoning. We checked for

549 multicollinearity, heteroscedasticity, and independent errors using a Durbin-Watson test ${ }^{91}$, and

550 found these to be in appropriate ranges.

551 To determine whether the relationship between training group and matrix reasoning (far transfer)

552 was mediated by near transfer, we conducted mediation analyses using ordinary least squares 
553 regression via the PROCESS macro in SPSS ${ }^{37}$. Performance on the Countermanding task was

554 entered as a parallel mediator. In the next step, each RCT was evaluated separately using the same

555 parallel two-mediator models. The independent variable was training group (N-back training,

556 Control), the mediators were average post-test performance on untrained N-back tasks and average

557 RT on incongruent trials of the Countermanding task, and the dependent variable was post-test

558 performance on Matrix Reasoning. Note that no mediator was modelled as influencing another

559 mediator in the model. To control for pre-existing individual differences in cognitive ability, we

560 entered performance for the three aforementioned tasks as covariates. Since the antecedent variable

561 is an experimental variable in a randomized study, its causal relation to the mediator and the

562 outcome variable can be interpreted unambiguously ${ }^{92,93}$. Since the post-test data was collected

563 within the same session, causality between the mediator and the outcome variable cannot be

564 established unequivocally; that said, we defend this causal claim on theoretical grounds, which

565 should be sufficient to allow for interpretation of the model ${ }^{37}$. However, to address this limitation,

566 in the replication study, near transfer performance preceded post-test performance on Matrix

567 Reasoning and other $\mathrm{G} f$ tasks by 1 day, hence it represents a plausible causal agent for these

568 outcome measures (see below).

\section{Pre-registered replication study}

\section{Participants}

572 A second experiment was conducted at the same universities in Summer and Fall of 2020 to

573 investigate whether the mediation model replicates in a double-blind RCT with two N-back

574 training groups and an active control group (cf. Table 2). The experiment was preregistered on

575 AsPredicted (\#40240) and was conducted online due to the COVID-19 pandemic. Participants 
576 were randomly assigned to one of three groups: Gamified N-back training, Non-gamified N-back

577 training, and General knowledge training (control group), with a target sample size of 64

578 participants per condition as determined by a power analysis for two-mediator models using Monte

579 Carlo simulations in MPLUS. We recruited 258 participants, 201 of which completed all training

580 and assessment sessions $\left(\mathrm{N}_{\text {Gamified N-back }}=70, \mathrm{~N}_{\text {Nongamifed } \mathrm{N} \text {-back }}=67, \mathrm{~N}_{\text {control }}=64\right)$. Participants

581 provided informed consent and received monetary compensation for participation; all procedures

582 were approved by UCR and UCI Institutional Review Boards. As can be seen in Table 4 and

583 Supplementary Table 6, sample demographics resemble those reported for the retrospective study.

584 Unless stated otherwise, procedures, tasks, and training details match those described in the 585 retrospective study.

587 Procedure

588 Since additional tasks were added to be able to examine latent constructs, the experiment consisted 589 of 3 pre-test and 3 post-test sessions, with 3-4 tasks per session to prevent fatigue associated with 590 prolonged testing. Supervision was provided via Zoom for all pre- and post-test sessions, as well 591 as the first training session, and any additional sessions as needed, along with technical support 592 via e-mail and phone. Different experimenters supervised pre/post-test sessions versus training 593 sessions to ensure experimenter blinding; likewise, participants were not aware that there were 594 multiple training conditions and which one they had been assigned to. 


\section{Training tasks}

$597 N$-back training. The same training task was used as in the retrospective study and participants 598 were encouraged to follow the same training protocol, i.e. to complete two 20-minute sessions per 599 day over the course of two weeks. The program was set up to prevent access to more than two 600 sessions in 24 hours. Participants were assigned to gamified or non-gamified N-back training as 601 described in the retrospective study. Half of the participants in each N-back training group trained 602 on a slightly different adaptive algorithm: miniblock-reset (each session starts at 2-back, level 603 up: $<3$ errors in 40-trial block, level down: $>6$ errors in 40-trial block) and online weighted accuracy

604 (level up: accuracy > 70\%, level down: accuracy < 50\%), which were collapsed for the purposes 605 of the current analysis.

606 General knowledge training. Participants in the active control group trained on a task that consists 607 of general knowledge, vocabulary, social science, and trivia multiple-choice questions as used 608 previously ${ }^{75,94}$. They were encouraged to follow the same schedule as the N-back training group 609 (two 20-minute sessions per day). This task was selected for the control intervention because it 610 taps into crystallized intelligence and should not engage fluid intelligence or WM. Previous 611 research has shown that participants find this task engaging and enjoyable ${ }^{30,75}$.

\section{Transfer measures}

613 The first and the last assessment sessions, which consisted of surveys and ETS and DAT tests,

614 were administered via Qualtrics (Qualtrics, Provo, UT), whereas the rest were implemented within

615 "Recollect the Study". All assessment sessions were supervised via video conferencing by a 616 researcher who was blind to the training condition the participant had been assigned to. Alternate 617 versions $^{51}$ of ETS Surface Development Test, ETS Form Board Test, and DAT Space Relations 
618 were grouped (As and Bs together) for administration at pre- and post-test, the order of which was

619 counterbalanced across participants. Alternate versions of Near transfer N-back, Running Span

620 and Matrix reasoning were administered at pre- and post-test in an counterbalanced order (A-B,

621 B-A).

622 Near transfer $N$-back. The same task was used as in the retrospective study, except that the vehicle

623 stimulus set was replaced with pictures of fruit. The main dependent variable, average accuracy

624 across 2-back and 3-back levels at pre-test, was comparable across experiments for the two

625 stimulus sets (Retrospective study - vehicles: Mean $_{\mathrm{pre}}=0.57, \mathrm{SD}_{\mathrm{pre}}=0.16$; Replication study: -

626 fruit: $\left.\mathrm{Mean}_{\mathrm{pre}}=0.60, \mathrm{SD}_{\mathrm{pre}}=0.14\right)$.

627 Running Span. An updating WM task in which participants saw an unpredictable number of stimuli

628 and were asked to report the last $\mathrm{N}$ items. The same stimuli were used as in Near transfer N-back

629 (animals and fruit), but with different stimulus sets presented at pre- and post-test across the two

630 tasks. Stimuli were presented for $500 \mathrm{~ms}$ with an ISI of $1500 \mathrm{~ms}$. Before each trial, the participants

631 were told how many items they will need to report. The response screen featured a "keyboard" of

632 pictures of 8 stimuli (always shown at the same locations) and the participants were asked to select

633 the last $\mathrm{N}$ pictures in order of appearance. The task started with 2 practice trials (set sizes 2 and 3 )

634 and if at least one trial was incorrect, practice was repeated. Feedback was provided during practice

635 but not during the assessment. The assessment consisted of set sizes 2-4 (in that order) with 3 trials

636 per set size. Progression to set size 5 (and beyond) was contingent upon having at least 2 out of 3

637 trials correct on the previous set size. The main dependent measure was the sum of all correctly

638 recalled items (partial score), whereby each item correctly chosen in the correct serial position was

639 assigned one point ${ }^{95}$. 
640 Sequencing. Participants were presented with a mixed sequence of letters and numbers that

641 appeared one by one, and were asked to enter the numbers in numerical order followed by letters

642 in alphabetical order ${ }^{59}$. The main dependent variable was the sum of all correctly recalled trials

643 (score).

644 Simple and Complex Spatial Span. Simple Span was used to assess spatial WM storage while

645 Complex Span was used to measure WM storage-and-processing ${ }^{96}$. In Simple Span, a sequence of 646 gophers appeared in 12 possible locations and the participants were tasked with reproducing the

647 sequence by tapping on the locations. In Complex Span, the same procedure was adopted, except

648 that in between each appearance of a gopher the participant completed a secondary sorting task

649 (dragging an item to the left or right). This secondary task presents interleaved processing demands

650 that are thought to limit the use of mnemonic strategies, such as chunking. In both tasks, set size

651 (i.e. the number of gopher locations in the sequence) ranged from 2 to 10; the test started with the

652 lowest set size and then increased (or decreased) using an adaptive algorithm. The main dependent

653 measure for each task was the sum of all correctly recalled items (partial-credit scoring ${ }^{97}$ ).

654 Countermanding. The same task was used as in the retrospective study.

655 Cancellation. A timed test of selective attention and inhibitory control that has been validated 656 against the D2 Test of Attention (Brickenkamp \& Zillmer, 1998)i. Participants were presented with 657 a series of rows featuring pictures of dogs or monkeys, some of which had inverted colors and 658 were reflected over the vertical axis or presented upside down. There were two types of targets: an 659 upright dog and an upside-down monkey and there were 3-5 of these targets per row. The goal was 660 to select all targets from left to right within a 6-second time limit. Each target type was practiced

\footnotetext{
${ }^{\mathrm{i}}$ Manuscript under review in Behavior Research Methods
} 
661 separately in 2 single blocks prior to proceeding to a mixed block. If a participant cleared a row

662 before the 6-second time limit, they could press a button to continue to the next row, thus,

663 participants completed bonus rows if a global time limit of 3 minutes and 10 seconds was not

664 exceeded. The main dependent measure was Concentration Performance ( $\sum$ Hits $-\sum$ False alarms)

665 in the mixed block.

666 Matrix reasoning. The same matrix reasoning task, UCMRT, was used as in RCT $2^{70}$.

667 ETS Surface Development Test ${ }^{75,98,99}$. Surface Development involves visualizing how a piece of

668 paper could be folded to form an object. Two images were presented on a computer screen: an

669 unfolded piece of paper and an object and participants were asked to mark which edges go together.

670 One practice problem was followed by 6 test problems, with a time limit of 6 minutes. The

671 dependent variable was the proportion of correct responses within the time limit.

672 ETS Form Board Test ${ }^{75,99,100}$. A given trial consisted of a set of five two-dimensional shapes that

673 can be combined into a two-dimensional geometrical shape presented above the set. The goal was

674 to indicate which of the pieces can be combined to match the geometrical shape given at the top

675 of the page. Participants were given two practice problems and then 8 minutes to solve 24

676 problems. The dependent variable was the proportion of correctly solved items in the given time

677 limit.

678 DAT Space Relations ${ }^{75,99,101}$ Participants were presented with a target pattern and four possible 679 objects and were asked to select the appropriate object into which the pattern can be folded. Two 680 practice problems proceeded 17 test items, with a 5-minute time limit to complete the test. The 681 dependent variable was the number of correctly solved items in the given time limit. 


\section{Outliers}

685 Out of 201 participants who completed the study, 6 participants were removed due to 686 administration error on ETS and DAT tests. Outliers were removed if a given data point was 3 or 687 more standard deviations from the mean at pre- or post-test. No outliers were removed for Near 688 Transfer or Matrix Reasoning; 6 outliers were removed based on Countermanding speed, hence 689 the resulting sample size was 189 (128 N-back training, 61 Active control; cf. Table 2). This 690 dataset was subject to initial replication mediation analyses. In the next step, additional outliers

691 were removed for Running Span $(\mathrm{N}=8)$ as well as 11 participants who showed non-compliance on 692 Sequencing and Spatial Span tasks. This second analytical dataset, which consisted of 170 693 participants (115 N-back training, 55 Active control) was used for the additional mediation 694 analyses that included additional assessments /composite scores.

\section{Composite variables}

697 Pre-test correlations of performance on the test battery revealed significant correlations among all 698 measures (cf. Table 5) except for Running Span, which correlated only with Sequencing, 699 moreover, it showed the lowest test-retest reliability among measures as indicated by the pre-post 700 correlation observed in the active control group $(r=.35)$, hence it was excluded from subsequent 701 analyses. Principal component analysis (PCA) with oblimin rotation was used to identify 702 composite scores. The sample size for PCA was adequate $(\mathrm{KMO}=.79)$, Bartlett's test of sphericity 703 was significant $(\chi 2(45)=387.55, \mathrm{p}<.001)$, the diagonals of the antiimage correlation matrix were

704 all over .7, and the communalities were all above .3, thereby confirming that each measure shared 705 some common variance with other measures. A three-factor solution was obtained, which 706 explained $58.5 \%$ of the variance (cf. Supplementary Table 7). The following factors were 
707 identified: inhibitory control (Countermanding, Cancellation), reasoning ability (UCMRT, ETS

708 Surface Development Test, ETS Form Board Test, DAT Space Relations), and working memory

709 (Near transfer N-back, Sequencing, Simple Span, and Complex Span), which is in line with the

710 theoretical structure proposed during preregistration. Composite variables were created by taking

711 the mean of z-transformed dependent variables which had their primary loadings on each factor.

712 Note that for models in which Near Transfer was used as a separate mediator, the WM composite

713 consisted only of Sequencing and Simple and Complex spatial span tasks. For IC, the values on

714 Countermanding were reversed so higher value indicates better performance.

715 Table 5: Pre-test correlations in the Replication Study. Shaded areas represent working memory

716 (WM), inhibitory control (IC) and reasoning (Gf) composites.

\begin{tabular}{|c|c|c|c|c|c|c|c|c|c|c|c|}
\hline & 1. & 2. & 3. & 4. & 5. & 6. & 7. & 8. & 9. & 10. & 11. \\
\hline 1. Near Transfer & 1.00 & & & & & & & & & & \\
\hline 2. Sequencing & $.30 * *$ & 1.00 & & & & & & & & & \\
\hline 3. Simple Span & $.24 * *$ & $.24 * *$ & 1.00 & & & & & & & & \\
\hline 4. Complex Span & $.25^{* *}$ & $.28 * *$ & $.48 * *$ & 1.00 & & & & & & & \\
\hline 5. Running Span & .12 & $.27 * *$ & .05 & .13 & 1.00 & & & & & & \\
\hline 6. Cancellation & $.29 * *$ & .14 & $.26^{* *}$ & $.38 * *$ & .04 & 1.00 & & & & & \\
\hline 7. Countermanding & $-.27 * *$ & -.11 & $-.26 * *$ & $-.29 * *$ & -.11 & $-.57 * *$ & 1.00 & & & & \\
\hline 8. UCMRT & $.27 * *$ & $.22 * *$ & $.27 * *$ & $.34 * *$ & .07 & $.28 * *$ & $-.27 * *$ & 1.00 & & & \\
\hline 9. ETS SD & $.29 * *$ & $.19 *$ & .13 & $.39 * *$ & .12 & $.25^{* *}$ & -.14 & $.47 * *$ & 1.00 & & \\
\hline 10. ETS SR & .13 & .09 & .11 & $.17 *$ & .15 & .02 & -.01 & $.22 * *$ & $.48 * *$ & 1.00 & \\
\hline 11. DAT FB & $.31 * *$ & $.22 * *$ & $.19 *$ & $.43^{* *}$ & $.17 *$ & $.27 * *$ & -.14 & $.37 * *$ & $.64 * *$ & $.44 * *$ & 1.00 \\
\hline
\end{tabular}

Note. $N=170 ; *=p<0.05, * *=p<0.01$. UCMRT $=$ Matrix reasoning task, ETS SD = Surface Development, ETS SR = Space Relations, DAT FB = Form Board. 
718 Acknowledgements: We would like to thank Cindy Collins, Audrey Carrillo, Rachel Smith-Pierce,

719 Randy Mester and Austin Moon and as well as our undergraduate research assistants for their help

720 with data collection, and Chandra Reynolds for statistical advice.

721 Funding: This work has been supported by the National Institute of Mental Health to ARS and 722 SMJ (Grant No. 1R01MH111742), and in addition, SMJ is supported by the National Institute on 723 Aging (Grant No. 1K02AG054665).

724 Competing Interests: SMJ has an indirect conflict of interest with the MIND Research Institute, 725 whose interests are related to this work.

726 Data Availability: The data that support the findings of this study are available from the 727 corresponding author upon reasonable request. 
732 1. McNab, F., Varrone, A., Farde, L., Jucaite, A., Bystritsky, P., Forssberg, H. \& Klingberg,

733 T. Changes in cortical dopamine D1 receptor binding associated with cognitive training.

$734 \quad$ Science 323, 800-802 (2009).

2. Park, D. C. \& Bischof, G. N. The aging mind: neuroplasticity in response to cognitive

3. Anguera, J. A., Boccanfuso, J., Rintoul, J. L., Al-Hashimi, O., Faraji, F., Janowich, J., Kong, E., Larraburo, Y., Rolle, C., Johnston, E. \& Gazzaley, A. Video game training enhances cognitive control in older adults. Nature 501, 97-101 (2013).

4. Mishra, J., de Villers-Sidani, E., Merzenich, M. \& Gazzaley, A. Adaptive training diminishes distractibility in aging across species. Neuron 84, 1091-1103 (2014).

5. Salmi, J., Nyberg, L. \& Laine, M. Working memory training mostly engages generalpurpose large-scale networks for learning. Neurosci. Biobehav. Rev. 93, 108-122 (2018).

6. Bäckman, L., Waris, O., Johansson, J., Andersson, M., Rinne, J. O., Alakurtti, K., Soveri, A., Laine, M. \& Nyberg, L. Increased dopamine release after working-memory updating training: Neurochemical correlates of transfer. Sci. Rep. 7, 7160 (2017).

7. Green, C. S. \& Seitz, A. R. The Impacts of Video Games on Cognition (and How the Government Can Guide the Industry). Policy Insights Behav. Brain Sci. 2, 101-110 (2015).

8. Deveau, J., Jaeggi, S. M., Zordan, V., Phung, C. \& Seitz, A. R. How to build better memory training games. Front. Syst. Neurosci. 8, 243 (2014).

9. Söderqvist, S., Bergman Nutley, S., Peyrard-Janvid, M., Matsson, H., Humphreys, K., Kere, J. \& Klingberg, T. Dopamine, working memory, and training induced plasticity: implications for developmental research. Dev. Psychol. 48, 836-843 (2012).

10. Mishra, J. \& Gazzaley, A. Closed-loop rehabilitation of age-related cognitive disorders. Semin Neurol 34, 584-590 (2014).

11. Au, J., Sheehan, E., Tsai, N., Duncan, G. J., Buschkuehl, M. \& Jaeggi, S. M. Improving fluid intelligence with training on working memory: a meta-analysis. Psychon. Bull. Rev. 22, 366-377 (2015).

12. Schwaighofer, M., Fischer, F. \& Bühner, M. Does Working Memory Training Transfer? A Meta-Analysis Including Training Conditions as Moderators. Educ Psychol 50, 138-166 (2015).

13. Soveri, A., Antfolk, J., Karlsson, L., Salo, B. \& Laine, M. Working memory training revisited: A multi-level meta-analysis of n-back training studies. Psychon. Bull. Rev. 24, 1077-1096 (2017).

14. Weicker, J., Villringer, A. \& Thöne-Otto, A. Can impaired working memory functioning be improved by training? A meta-analysis with a special focus on brain injured patients. Neuropsychology 30, 190-212 (2016).

15. Karbach, J. \& Verhaeghen, P. Making working memory work: a meta-analysis of executive-control and working memory training in older adults. Psychol. Sci. 25, 2027- 
2037 (2014).

16. Melby-Lervåg, M. \& Hulme, C. Is working memory training effective? A meta-analytic review. Dev. Psychol. 49, 270-291 (2013).

773

17. Melby-Lervåg, M. \& Hulme, C. There is no convincing evidence that working memory training is effective: A reply to Au et al. (2014) and Karbach and Verhaeghen (2014). Psychon. Bull. Rev. 23, 324-330 (2016).

18. Katz, B., Jones, M. R., Shah, P., Buschkuehl, M. \& Jaeggi, S. M. in Cognitive training. An Overview of Features and Applications. (eds. Strobach, T. \& Karbach, J.) 107-123 (Springer, 2021).

19. Pergher, V., Shalchy, M. A., Pahor, A., Van Hulle, M. M., Jaeggi, S. M. \& Seitz, A. R. Divergent research methods limit understanding of working memory training. J. Cogn. Enhanc. 1-21 (2019). doi:10.1007/s41465-019-00134-7

20. Burgess, G. C., Gray, J. R., Conway, A. R. A. \& Braver, T. S. Neural mechanisms of interference control underlie the relationship between fluid intelligence and working memory span. J. Exp. Psychol. Gen. 140, 674-692 (2011).

21. Gray, J. R., Chabris, C. F. \& Braver, T. S. Neural mechanisms of general fluid intelligence. Nat. Neurosci. 6, 316-322 (2003).

22. Hockey, A. \& Geffen, G. The concurrent validity and test?retest reliability of a visuospatial working memory task. Intelligence 32, 591-605 (2004).

23. Kane, M. J., Conway, A. R. A., Miura, T. K. \& Colflesh, G. J. H. Working memory, attention control, and the N-back task: a question of construct validity. J. Exp. Psychol. Learn. Mem. Cogn. 33, 615-622 (2007).

24. Jaeggi, S. M., Buschkuehl, M., Perrig, W. J. \& Meier, B. The concurrent validity of the Nback task as a working memory measure. Memory 18, 394-412 (2010).

25. Soveri, A., Karlsson, E. P. A., Waris, O., Grönholm-Nyman, P. \& Laine, M. Pattern of Near Transfer Effects Following Working Memory Training With a Dual N-Back Task. Exp. Psychol. 64, 240-252 (2017).

26. Buschkuehl, M., Hernandez-Garcia, L., Jaeggi, S. M., Bernard, J. A. \& Jonides, J. Neural effects of short-term training on working memory. Cogn Affect Behav Neurosci 14, 147160 (2014).

27. Küper, K. \& Karbach, J. Increased training complexity reduces the effectiveness of brief working memory training: evidence from short-term single and dual $n$-back training interventions. Journal of Cognitive Psychology 28, 199-208 (2016).

28. Barnett, S. M. \& Ceci, S. J. When and where do we apply what we learn? A taxonomy for far transfer. Psychol. Bull. 128, 612-637 (2002).

29. Harty, S., Sella, F. \& Cohen Kadosh, R. Mind the brain: the mediating and moderating role of neurophysiology. Trends Cogn. Sci. (Regul. Ed.) 21, 2-5 (2017).

30. Jaeggi, S. M., Buschkuehl, M., Jonides, J. \& Shah, P. Short- and long-term benefits of cognitive training. Proc. Natl. Acad. Sci. USA 108, 10081-10086 (2011).

31. Laine, M., Fellman, D., Waris, O. \& Nyman, T. J. The early effects of external and internal 
strategies on working memory updating training. Sci. Rep. 8, 4045 (2018).

32. Katz, B., Jaeggi, S. M., Buschkuehl, M., Shah, P. \& Jonides, J. The effect of monetary compensation on cognitive training outcomes. Learn Motiv 63, 77-90 (2018).

33. Wagenmakers, E.-J., Love, J., Marsman, M., Jamil, T., Ly, A., Verhagen, J., Selker, R., Gronau, Q. F., Dropmann, D., Boutin, B., Meerhoff, F., Knight, P., Raj, A., van Kesteren, E.-J., van Doorn, J., Šmíra, M., Epskamp, S., Etz, A., Matzke, D., de Jong, T., van den Bergh, D., Sarafoglou, A., Steingroever, H., Derks, K., Rouder, J. N. \& Morey, R. D. Bayesian inference for psychology. Part II: Example applications with JASP. Psychon. Bull. Rev. 25, 58-76 (2018).

34. Lee, M. D. \& Wagenmakers, E.-J. Bayesian cognitive modeling: A practical course. (Cambridge University Press, 2013). doi:10.1017/CBO9781139087759

35. Boot, W. R., Simons, D. J., Stothart, C. \& Stutts, C. The Pervasive Problem With Placebos in Psychology: Why Active Control Groups Are Not Sufficient to Rule Out Placebo Effects. Perspect. Psychol. Sci. 8, 445-454 (2013).

36. Au, J., Gibson, B. C., Bunarjo, K., Buschkuehl, M. \& Jaeggi, S. M. Quantifying the Difference Between Active and Passive Control Groups in Cognitive Interventions Using Two Meta-analytical Approaches. J. Cogn. Enhanc. 4, 192-210 (2020).

37. Hayes, A. F. in Introduction to mediation, moderation, and conditional process analysis: A regression-based approach 77-112 (Guilford Press, 2018).

38. Tate, C. U. On the overuse and misuse of mediation analysis: it may be a matter of timing. Basic Appl. Soc. Psych. 37, 235-246 (2015).

39. Zinke, K., Zeintl, M., Rose, N. S., Putzmann, J., Pydde, A. \& Kliegel, M. Working memory training and transfer in older adults: effects of age, baseline performance, and training gains. Dev. Psychol. 50, 304-315 (2014).

40. Rudebeck, S. R., Bor, D., Ormond, A., O’Reilly, J. X. \& Lee, A. C. H. A potential spatial working memory training task to improve both episodic memory and fluid intelligence. PLoS One 7, e50431 (2012).

41. Tidwell, J. W., Dougherty, M. R., Chrabaszcz, J. R., Thomas, R. P. \& Mendoza, J. L. What counts as evidence for working memory training? Problems with correlated gains and dichotomization. Psychon. Bull. Rev. 21, 620-628 (2014).

42. Chuderski, A. \& Necka, E. The contribution of working memory to fluid reasoning: capacity, control, or both? J. Exp. Psychol. Learn. Mem. Cogn. 38, 1689-1710 (2012).

43. Friedman, N. P., Miyake, A., Corley, R. P., Young, S. E., Defries, J. C. \& Hewitt, J. K. Not all executive functions are related to intelligence. Psychol. Sci. 17, 172-179 (2006).

44. Halford, G. S., Cowan, N. \& Andrews, G. Separating cognitive capacity from knowledge: a new hypothesis. Trends Cogn. Sci. (Regul. Ed.) 11, 236-242 (2007).

45. Carpenter, P. A., Just, M. A. \& Shell, P. What one intelligence test measures: a theoretical account of the processing in the Raven Progressive Matrices Test. Psychol. Rev. 97, 404431 (1990).

46. Unsworth, N. \& Engle, R. Working memory capacity and fluid abilities: Examining the 
correlation between Operation Span and Raven. Intelligence 33, 67-81 (2005).

47. Wiley, J., Jarosz, A. F., Cushen, P. J. \& Colflesh, G. J. H. New rule use drives the relation between working memory capacity and Raven's Advanced Progressive Matrices. J. Exp. Psychol. Learn. Mem. Cogn. 37, 256-263 (2011).

48. Jarosz, A. F. \& Wiley, J. Why does working memory capacity predict RAPM performance? A possible role of distraction. Intelligence 40, 427-438 (2012).

49. Harrison, T. L., Shipstead, Z. \& Engle, R. W. Why is working memory capacity related to

50. Shipstead, Z., Harrison, T. L. \& Engle, R. W. Working memory capacity and fluid matrix reasoning tasks? Mem. Cognit. 43, 389-396 (2015).

intelligence: maintenance and disengagement. Perspect. Psychol. Sci. 11, 771-799 (2016).

51. Dahlin, E., Neely, A. S., Larsson, A., Bäckman, L. \& Nyberg, L. Transfer of learning after updating training mediated by the striatum. Science 320, 1510-1512 (2008).

52. Engle, R. W. Working memory and executive attention: A revisit. Perspect. Psychol. Sci. 13, 190-193 (2018).

53. Li, W., Zhang, Q., Qiao, H., Jin, D., Ngetich, R. K., Zhang, J., Jin, Z. \& Li, L. Dual n-back working memory training evinces superior transfer effects compared to the method of loci. Sci. Rep. 11, 3072 (2021).

54. Lilienthal, L., Tamez, E., Shelton, J. T., Myerson, J. \& Hale, S. Dual n-back training increases the capacity of the focus of attention. Psychon. Bull. Rev. 20, 135-141 (2013).

55. Chein, J. M. \& Morrison, A. B. Expanding the mind's workspace: training and transfer effects with a complex working memory span task. Psychon. Bull. Rev. 17, 193-199 (2010).

56. Borella, E., Carretti, B., Riboldi, F. \& De Beni, R. Working memory training in older adults: evidence of transfer and maintenance effects. Psychol. Aging 25, 767-778 (2010).

57. Schwarb, H., Nail, J. \& Schumacher, E. H. Working memory training improves visual short-term memory capacity. Psychol. Res. 80, 128-148 (2016).

58. Stepankova, H., Lukavsky, J., Buschkuehl, M., Kopecek, M., Ripova, D. \& Jaeggi, S. M. The malleability of working memory and visuospatial skills: a randomized controlled study in older adults. Dev. Psychol. 50, 1049-1059 (2014).

59. Pahor, A., Collins, C., Smith-Peirce, R. N., Moon, A., Stavropoulos, T., Silva, I., Peng, E., Jaeggi, S. M. \& Seitz, A. R. Multisensory facilitation of working memory training. $J$. Cogn. Enhanc. (2020). doi:10.1007/s41465-020-00196-y

60. Linares, R., Borella, E., Lechuga, M. T., Carretti, B. \& Pelegrina, S. Nearest transfer effects of working memory training: A comparison of two programs focused on working memory updating. PLoS One 14, e0211321 (2019).

61. Blacker, K. J., Negoita, S., Ewen, J. B. \& Courtney, S. M. N-back versus Complex Span Working Memory Training. J. Cogn. Enhanc. 1, 434-454 (2017).

62. Chooi, W.-T. \& Thompson, L. A. Working memory training does not improve intelligence in healthy young adults. Intelligence 40, 531-542 (2012).

63. Li, S.-C., Schmiedek, F., Huxhold, O., Röcke, C., Smith, J. \& Lindenberger, U. Working 
memory plasticity in old age: practice gain, transfer, and maintenance. Psychol. Aging 23, 731-742 (2008).

64. Thompson, T. W., Waskom, M. L., Garel, K.-L. A., Cardenas-Iniguez, C., Reynolds, G. O., Winter, R., Chang, P., Pollard, K., Lala, N., Alvarez, G. A. \& Gabrieli, J. D. E. Failure of working memory training to enhance cognition or intelligence. PLoS One 8, e63614 (2013).

65. Minear, M., Brasher, F., Guerrero, C. B., Brasher, M., Moore, A. \& Sukeena, J. A simultaneous examination of two forms of working memory training: Evidence for near transfer only. Mem. Cognit. 44, 1014-1037 (2016).

66. Redick, T. S., Shipstead, Z., Harrison, T. L., Hicks, K. L., Fried, D. E., Hambrick, D. Z., Kane, M. J. \& Engle, R. W. No evidence of intelligence improvement after working memory training: a randomized, placebo-controlled study. J. Exp. Psychol. Gen. 142, 359379 (2013).

67. Schweizer, S., Hampshire, A. \& Dalgleish, T. Extending brain-training to the affective domain: increasing cognitive and affective executive control through emotional working memory training. PLoS One 6, e24372 (2011).

68. Jones, M. R., Katz, B., Buschkuehl, M., Jaeggi, S. M. \& Shah, P. Exploring N-Back Cognitive Training for Children With ADHD. J Atten Disord 1087054718779230 (2018). doi:10.1177/1087054718779230

69. Maraver, M. J., Bajo, M. T. \& Gomez-Ariza, C. J. Training on working memory and inhibitory control in young adults. Front. Hum. Neurosci. 10, 588 (2016).

70. Pahor, A., Stavropoulos, T., Jaeggi, S. M. \& Seitz, A. R. Validation of a matrix reasoning task for mobile devices. Behav. Res. Methods (2018). doi:10.3758/s13428-018-1152-2

71. Simons, D. J., Boot, W. R., Charness, N., Gathercole, S. E., Chabris, C. F., Hambrick, D. Z. \& Stine-Morrow, E. A. L. Do "Brain-Training" Programs Work? Psychol. Sci. Public Interest 17, 103-186 (2016).

72. Borella, E., Carretti, B., Sciore, R., Capotosto, E., Taconnat, L., Cornoldi, C. \& De Beni, R. Training working memory in older adults: Is there an advantage of using strategies? Psychol. Aging 32, 178-191 (2017).

73. Fellman, D., Jylkkä, J., Waris, O., Soveri, A., Ritakallio, L., Haga, S., Salmi, J., Nyman, T. J. \& Laine, M. The role of strategy use in working memory training outcomes. J. Mem. Lang. 110, 104064 (2020).

74. Katz, B., Jones, M. R., Shah, P., Buschkuehl, M. \& Jaeggi, S. M. in Cognitive Training (eds. Strobach, T. \& Karbach, J.) 157-166 (Springer International Publishing, 2016). doi:10.1007/978-3-319-42662-4_15

75. Jaeggi, S. M., Buschkuehl, M., Shah, P. \& Jonides, J. The role of individual differences in cognitive training and transfer. Mem. Cognit. 42, 464-480 (2014).

76. López-Alonso, V., Cheeran, B., Río-Rodríguez, D. \& Fernández-Del-Olmo, M. Interindividual variability in response to non-invasive brain stimulation paradigms. Brain Stimulat. 7, 372-380 (2014). 
77. Bailey, N. W., Hoy, K. E., Rogasch, N. C., Thomson, R. H., McQueen, S., Elliot, D., Sullivan, C. M., Fulcher, B. D., Daskalakis, Z. J. \& Fitzgerald, P. B. Responders to rTMS for depression show increased fronto-midline theta and theta connectivity compared to non-responders. Brain Stimulat. 11, 190-203 (2018).

78. Reid, G., Gaudier, E., Guarner, F., Huffnagle, G. B., Macklaim, J. M., Munoz, A. M., Martini, M., Ringel-Kulka, T., Sartor, B., Unal, R., Verbeke, K., Walter, J. \& International Scientific Association for Probiotics and Prebiotics. Responders and non-responders to probiotic interventions: how can we improve the odds? Gut Microbes 1, 200-204 (2010).

79. Salas-Pérez, F., Cuevas-Sierra, A., Cuervo, M., Goni, L., Milagro, F. I., Martínez, J. A. \& Riezu-Boj, J. I. Differentially methylated regions (DMRs) in PON3 gene between responders and non-responders to a weight loss dietary intervention: a new tool for precision management of obesity. Epigenetics 1-12 (2021). doi:10.1080/15592294.2021.1873629

80. Ostojic, S. M. Short-term GAA loading: Responders versus nonresponders analysis. Food Sci. Nutr. 8, 4446-4448 (2020).

81. Pickering, C. \& Kiely, J. Do Non-Responders to Exercise Exist-and If So, What Should We Do About Them? Sports Med. 49, 1-7 (2019).

82. Tullo, D. \& Jaeggi, S. M. in The Cambridge Handbook of Working Memory and Language. (eds. Schwieter, W. \& Zen, Z.) (Cambridge University Press).

83. Schork, N. J. Personalized medicine: Time for one-person trials. Nature 520, 609-611 (2015).

84. Peretz, C., Korczyn, A. D., Shatil, E., Aharonson, V., Birnboim, S. \& Giladi, N. Computerbased, personalized cognitive training versus classical computer games: a randomized double-blind prospective trial of cognitive stimulation. Neuroepidemiology 36, 91-99 (2011).

85. Shatil, E., Metzer, A., Horvitz, O. \& Miller, A. Home-based personalized cognitive training in MS patients: a study of adherence and cognitive performance.

NeuroRehabilitation 26, 143-153 (2010).

86. Sandeep, S., Shelton, C. R., Pahor, A., Jaeggi, S. M. \& Seitz, A. R. Application of machine learning models for tracking participant skills in cognitive training. Front. Psychol. 11, 1532 (2020).

87. Matzen, L. E., Benz, Z. O., Dixon, K. R., Posey, J., Kroger, J. K. \& Speed, A. E. Recreating Raven's: software for systematically generating large numbers of Raven-like matrix problems with normed properties. Behav. Res. Methods 42, 525-541 (2010).

88. Davidson, M. C., Amso, D., Anderson, L. C. \& Diamond, A. Development of cognitive control and executive functions from 4 to 13 years: evidence from manipulations of memory, inhibition, and task switching. Neuropsychologia 44, 2037-2078 (2006).

89. Ramani, G. B., Daubert, E. N., Lin, G. C., Kamarsu, S., Wodzinski, A. \& Jaeggi, S. M. Racing dragons and remembering aliens: Benefits of playing number and working memory games on kindergartners' numerical knowledge. Dev. Sci. 23, e12908 (2020). 
90. JASP Team. JASP 0.9.2. (Computer software, 2019).

91. Field, A. in Discovering Statistics using IBM SPSS Statistics 293-356 (Sage Publications Ltd., 2013).

973 92. Holland, P. W. Statistics and causal inference. J. Am. Stat. Assoc. 81, 945-960 (1986).

974 93. Shrout, P. E. \& Bolger, N. Mediation in experimental and nonexperimental studies: new procedures and recommendations. Psychol. Methods 7, 422-445 (2002).

94. Jaeggi, S. M., Buschkuehl, M., Parlett-Pelleriti, C. M., Moon, S. M., Evans, M., Kritzmacher, A., Reuter-Lorenz, P. A., Shah, P. \& Jonides, J. Investigating the effects of spacing on working memory training outcome - a randomized controlled multi-site trial in older adults. J. Gerontol. B, Psychol. Sci. Soc. Sci. (2019). doi:10.1093/geronb/gbz090

95. Broadway, J. M. \& Engle, R. W. Validating running memory span: measurement of working memory capacity and links with fluid intelligence. Behav. Res. Methods 42, 563570 (2010).

96. Cowan, N. What are the differences between long-term, short-term, and working memory? Prog. Brain Res. 169, 323-338 (2008).

97. Conway, A. R. A., Kane, M. J., Bunting, M. F., Hambrick, D. Z., Wilhelm, O. \& Engle, R. W. Working memory span tasks: A methodological review and user's guide. Psychon. Bull. Rev. 12, 769-786 (2005).

98. Ekstrom, R. B. ETS Kit of Factor-Referenced Cognitive Tests. (Educational Testing Service, 1976).

99. Kane, M. J., Hambrick, D. Z., Tuholski, S. W., Wilhelm, O., Payne, T. W. \& Engle, R. W. The generality of working memory capacity: a latent-variable approach to verbal and visuospatial memory span and reasoning. J. Exp. Psychol. Gen. 133, 189-217 (2004).

100. Ekstrom, R. B., French, J. W., Harmon, H. H. \& Derman, D. ETS Kit of Factor-Referenced Cognitive Tests. (1976).

101. Bennett, G. K., Seashore, H. G. \& Wesman, A. G. Differential Aptitude Test: Space Relations. (1972). 